\title{
Entrapped Transient Chloroform Solvates of Bilastine
}

\author{
Cristina Puigjaner ${ }^{1, * \mathbb{D}}$, Anna Portell ${ }^{1}$, Arturo Blasco ${ }^{2}$, Mercè Font-Bardia $^{1}$ and Oriol Vallcorba $^{3} \mathbb{D}$ \\ 1 Centres Científics i Tecnològics, Universitat de Barcelona, Lluís Solé i Sabarís 1-3, 08028 Barcelona, Spain; \\ portell@ccit.ub.edu (A.P.); mercef@ccit.ub.edu (M.F.-B.) \\ 2 Institut Químic de Sarrià, Universitat Ramon Llull, Via Augusta 390, 08017 Barcelona, Spain; \\ arturoblascos@iqs.edu \\ 3 ALBA Synchrotron Light Source, Carrer de la Llum 2-26, Cerdanyola del Vallès, 08290 Barcelona, Spain; \\ ovallcorba@cells.es \\ * Correspondence: cris@ccit.ub.edu; Tel.: +34-93-4021692
}

check for updates

Citation: Puigjaner, C.; Portell, A.; Blasco, A.; Font-Bardia, M.; Vallcorba O. Entrapped Transient Chloroform Solvates of Bilastine. Crystals 2021, 11, 342. https://doi.org/10.3390/cryst 11040342

Academic Editor: Venu Vangala

Received: 14 March 2021

Accepted: 24 March 2021

Published: 28 March 2021

Publisher's Note: MDPI stays neutral with regard to jurisdictional claims in published maps and institutional affiliations.

Copyright: (c) 2021 by the authors. Licensee MDPI, Basel, Switzerland. This article is an open access article distributed under the terms and conditions of the Creative Commons Attribution (CC BY) license (https:// creativecommons.org/licenses/by/ $4.0 /)$.

\begin{abstract}
The knowledge about the solid forms landscape of Bilastine (BL) has been extended. The crystal structures of two anhydrous forms have been determined, and the relative thermodynamic stability among the three known anhydrous polymorphs has been established. Moreover, three chloroform solvates with variable stoichiometry have been identified and characterized, showing that $\mathrm{S}_{3 \mathrm{CHCl} 3-\mathrm{H} 2 \mathrm{O}}$ and $\mathrm{S}_{\mathrm{CHCl} 3}$ can be classified as transient solvates which transform into the new chloroform solvate $\mathrm{S}_{\mathrm{CHCl} 3-\mathrm{H} 2 \mathrm{O}}$ when removed from the mother liquor. The determination of their crystal structures from combined single crystal/synchrotron X-ray powder diffraction data has allowed the complete characterization of these solvates, being two of them heterosolvates $\left(\mathrm{S}_{3 \mathrm{CHCl} 3-\mathrm{H} 2 \mathrm{O}}\right.$ and $\left.\mathrm{S}_{\mathrm{CHCl} 3-\mathrm{H} 2 \mathrm{O}}\right)$ and $\mathrm{S}_{\mathrm{CHCl} 3}$ a monosolvate. Moreover, the temperature dependent stability and interrelation pathways among the chloroform solvates and the anhydrous forms of BL have been studied.
\end{abstract}

Keywords: solvate; polymorph; bilastine; crystal structure determination; single crystal X-ray diffraction; structure determination from powder diffraction

\section{Introduction}

A search for the different solid forms of an active pharmaceutical ingredient (API) is a crucial part of the drug development process. Solvate formation has many implications in the pharmaceutical industry, as it affects the physicochemical properties of materials, such as their melting point, density and dissolution rate, which in turn can influence their manufacturability and pharmacokinetic properties, without changing the pharmacology of the API through modification of covalent bonds [1-4]. The unexpected formation of undesired solvates can thus lead to unpredictable behavior of the drug and could prove costly. Organic solvents are constantly present in the pharmaceutical production processes, so many aspects of them have to be extremely controlled [5].

The rationalization of the solvate formation is one of the important topics in the current crystal engineering [6], and the discovery of solvates is important in several aspects: (1) formation of solvates can limit the selection of solvents for crystallization of the desired crystal form; (2) solvates can be used as intermediates for producing the necessary polymorphs, as specific polymorphs can sometimes be obtained only via desolvation of particular solvates; (3) solvates can serve to control the particle size distribution in the product in cases in which the nonsolvated forms are difficult to crystallize [6]; and (4) particularly stable solvates, typically but not exclusively hydrates (like diosgenin hydrate [7] for example), can be used as the marketed form [8]. Although the utilization of the most physically stable crystal form is typically desired as any change in the solid form may affect the bioavailability associated with the drug product, metastable modifications can be preferred when an improvement in the in vitro dissolution kinetics is achieved. Up to the present, there are some few solvates on the market such as trametinib dimethyl sulfoxide, dapaglifozin propanediol monohydrate, cabazitaxel, darunavir ethanolate, warfarin sodium, indinavir sulfate ethanolate and 
atorvastatin calcium [9]. Limitations for the use of solvates in pharmaceutical industry are given by the toxicity of solvents they contain, and also, they may additionally accelerate decomposition of the final product. Permitted solvents and the limits of their content are provided by the regulatory authorities in the pharmacopeias [10].

The general prediction of solvate formation, similar to the prediction of other solid forms, is still largely an unresolved problem. Currently, in order to avoid unexpected structural transformations such as hydrate and solvate forms, in the pharmaceutical industry, high-throughput crystallization experiments are conducted to obtain all possible solid forms of a drug [11].

Two main structural driving forces responsible for incorporation of solvent molecules in the structure have been identified, on one hand, the ability of solvents to compensate unsatisfied potential intermolecular interactions between the molecules and, on the other hand, the ability to decrease the void space and/or lead to more efficient packing. Both the formation of an extensive hydrogen bond network established by the solvent molecules as well as an increase of the packing efficiency have been shown to be the main contributing factors for the solvate formation of pharmaceutical molecules. Most of the solvates, however, include contributions from both of these driving forces, and the solvate formation thus is due to a lowering of the crystal free energy [8].

Bilastine, 2-[4-[2-[4-[1-(2-ethoxyethyl)-1H-benzimidazol-2-yl]-1-piperidinyl]ethyl] phenyl]2-methylpropionic acid (Figure 1), is a well-tolerated, second generation antihistamine drug approved for the symptomatic treatment of allergic rhinoconjunctivitis and chronic urticaria [12]. It exerts its effect as a selective histamine $\mathrm{H}_{1}$ receptor antagonist and has an effectiveness similar to cetirizine, fexofenadine and desloratadine [13]. It was developed in Spain by FAES Farma, and it has been commercially available internationally since March 2011.

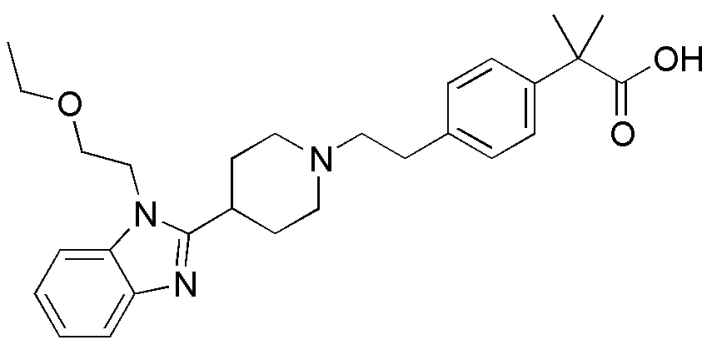

Figure 1. Chemical structure of Bilastine.

$\mathrm{BL}$, its preparation and uses as $\mathrm{H} 1$ receptor antagonist were first described in the European patent EP0818454B1 [14]. Later, the patent WO03089425 reported three crystalline forms of BL: 1, 2 and 3, characterized by IR, and crystallographic parameters were provided only for form 1 [15]. It was said that forms 2 and 3 of BL easily converted into form 1 . In the present study we have extended the knowledge about the solid forms landscape of BL by performing a polymorph screening starting from anhydrous forms I and III, whose crystal structures have been determined from single crystal and synchrotron powder X-ray diffraction, respectively. The thermodynamic relationship among the anhydrous forms has been established. In addition, during the screening three chloroform solvates (two heterosolvates $\left(\mathrm{S}_{3 \mathrm{CHCl} 3-\mathrm{H} 2 \mathrm{O}}\right.$ and $\mathrm{S}_{\mathrm{CHCl} 3-\mathrm{H} 2 \mathrm{O}}$ ) and one monosolvate $\mathrm{S}_{\mathrm{CHCl} 3}$ ) have been obtained, being two of them transient solvates which transform into solvate $\mathrm{S}_{\mathrm{CHCl} 3-\mathrm{H} 2 \mathrm{O}}$ immediately when exposed to ambient conditions. The crystal structures of the three solvates with different stoichiometries have been determined and will be discussed and compared with the anhydrous forms. Moreover, the different forms have been further characterized by differential scanning calorimetry (DSC), thermogravimetric analysis (TGA) and variable temperature powder X-ray diffraction (VT-PXRD). Finally, the phase transformations pathways among the different forms have been defined. 


\section{Materials and Methods}

\subsection{Preparation of Bilastine Crystal Forms}

The organic solvents used were all of analytical quality. The screen included evaporations, cooling crystallizations at different rates, antisolvent precipitations, antisolvent diffusions and slurries (see details in the Supplementary Materials). The experimental solid form screening resulted in six solid forms (three anhydrates and three chloroform solvates) as confirmed by PXRD and thermal analysis.

\subsubsection{Form I}

BL $(40 \mathrm{mg})(0.086 \mathrm{mmol})$ was dissolved in $\mathrm{DCM}(0.7 \mathrm{~mL})$ at $60^{\circ} \mathrm{C}$, and the solution was slowly cooled down to $25^{\circ} \mathrm{C}$. After 18 days, single crystals were obtained, filtered, dried under vacuum and analyzed by SCXRD.

\subsubsection{Form II}

Form III of BL $(20 \mathrm{mg})(0.043 \mathrm{mmol})$ was placed in a $70 \mu \mathrm{L}$ alumina crucible and heated under nitrogen atmosphere inside a TGA equipment from $30{ }^{\circ} \mathrm{C}$ to $200{ }^{\circ} \mathrm{C}$ at a rate of $10{ }^{\circ} \mathrm{C} / \mathrm{min}$, maintained at $200{ }^{\circ} \mathrm{C}$ for $5 \mathrm{~min}$ and cooled down to $30^{\circ} \mathrm{C}$.

\subsubsection{Form III}

BL $(100 \mathrm{mg})(0.216 \mathrm{mmol})$ was dissolved in $\mathrm{CHCl}_{3}(0.6 \mathrm{~mL})$ at $60^{\circ} \mathrm{C}$, and the solution was cooled down to $25^{\circ} \mathrm{C}$ outside the heating block. The solid precipitated after one night and it was filtered and dried under vacuum.

\subsection{4. $\mathrm{S}_{3 \mathrm{CHCl}}-\mathrm{H} 2 \mathrm{O}$}

$\mathrm{CHCl}_{3}(2.3 \mathrm{~mL})$ was added to $330 \mathrm{mg}$ of $\mathrm{BL}$ at $60^{\circ} \mathrm{C}$. The solution was cooled down overnight and left in the fridge $\left(4-5{ }^{\circ} \mathrm{C}\right)$ for four days until single crystal growing. This solvate was stable in the mother liquor. The single crystal was analyzed by SCXRD at low

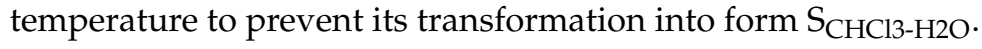

\subsection{5. $\mathrm{S}_{\mathrm{CHCl} 3-\mathrm{H} 2 \mathrm{O}}$}

$\mathrm{CHCl}_{3}(6.5 \mathrm{~mL})$ was added to $1 \mathrm{~g}$ of $\mathrm{BL}$, and the resulting suspension was stirred overnight at r.t. The solid was filtered and dried under vacuum.

\subsection{6. $\mathrm{S}_{\mathrm{CHCl} 3}$}

BL $(45 \mathrm{mg})$ was dissolved in the minimum quantity of anhydrous $\mathrm{CHCl}_{3}(0.35 \mathrm{~mL})$ at $90{ }^{\circ} \mathrm{C}$. The solution was cooled down inside the fridge $\left(4-5^{\circ} \mathrm{C}\right)$ until single crystal growing. This solvate was stable in the mother liquor. The single crystal was analyzed by SCXRD at low temperature to prevent its transformation into form $\mathrm{S}_{\mathrm{CHCl3}-\mathrm{H} 2 \mathrm{O}}$.

\subsection{Methods}

\subsubsection{Powder X-ray Diffraction (PXRD)}

Powder X-ray diffraction patterns were obtained on a PANalytical X'Pert PRO MPD diffractometer (Malvern Panalytical, Almelo, Netherlands) in transmission configuration using $\mathrm{Cu} \mathrm{K} \alpha 1+2$ radiation $(\lambda=1.5418 \AA)$ with a focalizing elliptic mirror and a PIXcel detector working at a maximum detector's active length of $3.347^{\circ}$. Capillary geometry has been used with samples placed in glass capillaries (Lindemman) of $0.5 \mathrm{~mm}$ of diameter measuring from 2 to $60^{\circ}$ in $2 \theta$, with a step size of $0.026^{\circ}$ and a total measuring time of $30 \mathrm{~min}$. Flat geometry has been used for routine samples sandwiched between low absorbing films (polyester of 3.6 microns of thickness) measuring 2theta/theta scans from 2 to $40^{\circ}$ in $2 \theta$ with a step size of $0.026^{\circ}$ and a measuring time of 80 seconds per step.

Powder X-ray diffraction patterns of forms III and $\mathrm{S}_{\mathrm{CHCl3}-\mathrm{H} 2 \mathrm{O}}$ were obtained using synchrotron radiation at ALBA's beam line BL04-MSPD using Mythen detector [16]. The

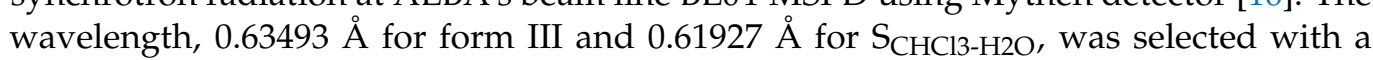
double-crystal Si (111) monochromator and determined from a Si640d NIST standard 
( $a=5.43123 \AA$ ) measurement. The diffractometer is equipped with a so-called MYTHEN detector system especially suited for time-resolved experiments. The capillary of $0.7 \mathrm{~mm}$ containing the sample was rotated during data collection to improve diffracting particle statistics. The data acquisition time was $10 \mathrm{~min}$ per pattern, and the final treated data are the addition of ten acquisitions to attain very good signal-to-noise ratio over the angular range $0.5-43.6^{\circ}(2 \theta)$ at $300 \mathrm{~K}$. Both powder diffraction patterns were indexed using DICVOL06 [17], and the obtained cell parameters were refined via pattern matching with Dajust software [18]. The crystal structures were solved with the direct-space strategy TALP [19] introducing the bond distances and angles from the single crystal structure of form I as restraints. Crystal structure solution was followed by the location of the solvent molecules in the difference electron density map and a restrained Rietveld refinement with RIBOLS to obtain the final crystal structures. $\mathrm{H}$-atoms were placed to calculated positions after the final refinement.

Variable temperature experiments of $\mathrm{S}_{3 \mathrm{CHCl}-\mathrm{H} 2 \mathrm{O}}$ sample were performed at the ALBA Synchrotron using a Cyberstar hot gas blower with an Eurotherm temperature controller (Eurotherm, Worthing, UK) and continuously collecting diffraction data during the heating and cooling ramps $\left(30^{\circ}\right.$ to $230^{\circ}$ and $230^{\circ}$ to $30^{\circ}$ at $2^{\circ} / \mathrm{min}, 18 \mathrm{sec} /$ pattern). A longer measurement (180s) was performed at room temperature.

\subsubsection{Single Crystal X-ray Diffraction (SCXRD)}

The single crystal structures were solved on a D8 (Bruker, Karlsrühe, Germany) Venture system equipped with a multilayer monochromator, and a Mo microfocus $(\lambda=0.71073 \AA)$ has been used too. Frames were integrated with the Bruker SAINT software package using a SAINT algorithm. Data were corrected for absorption effects using the multi-scan method (SADABS). The structures were solved and refined using the Bruker SHELXTL Software Package [20], a computer program for automatic solution of crystal structure, and refined by full-matrix least-squares method with ShelXle Version 4.8.0, a Qt graphical user interface for SHELXL computer program [21].

\subsubsection{Differential Scanning Calorimetry (DSC)}

Differential scanning calorimetry was carried out by means of a Mettler-Toledo DSC822e calorimeter (Mettler-ToledoAG, Schwerzenbach, Switzerland). Experimental conditions: Aluminum crucibles of $40 \mu \mathrm{L}$ volume, atmosphere of dry nitrogen with $50 \mathrm{~mL} / \mathrm{min}$ flow rate, heating rate of $10{ }^{\circ} \mathrm{C} / \mathrm{min}$. The calorimeter was calibrated with indium of $99.99 \%$ purity.

\subsubsection{Thermogravimetric Analysis (TGA)}

Thermogravimetric analyses were performed to detect the presence of hydrates/solvates on a Mettler-Toledo TGA-851e thermobalance (Mettler-ToledoAG, Schwerzenbach, Switzerland). Experimental conditions: Alumina crucibles of $70 \mu \mathrm{L}$ volume, atmosphere of dry nitrogen with $50 \mathrm{~mL} / \mathrm{min}$ flow rate, heating rate of $10^{\circ} \mathrm{C} / \mathrm{min}$.

\section{Results and Discussion}

\subsection{Anhydrous Forms}

Three anhydrous forms of BL have been identified. According to their melting points (Figure 2), forms I, II and III correspond to polymorphs 1, 2 and 3 previously reported in patent WO03089425. The DSC of the lowest melting form III shows its melting and simultaneous crystallization and melting of form I followed by the crystallization and melting of form II, the highest melting form.

High quality single crystals suitable for crystal structure determination have been obtained only for Form I, while the crystal structure of form III was determined from PXRD data obtained in Synchrotron. Regarding form II, only its unit cell and space group could be determined. The X-ray powder diffractograms of the three anhydrous forms are shown in Figure 3. 


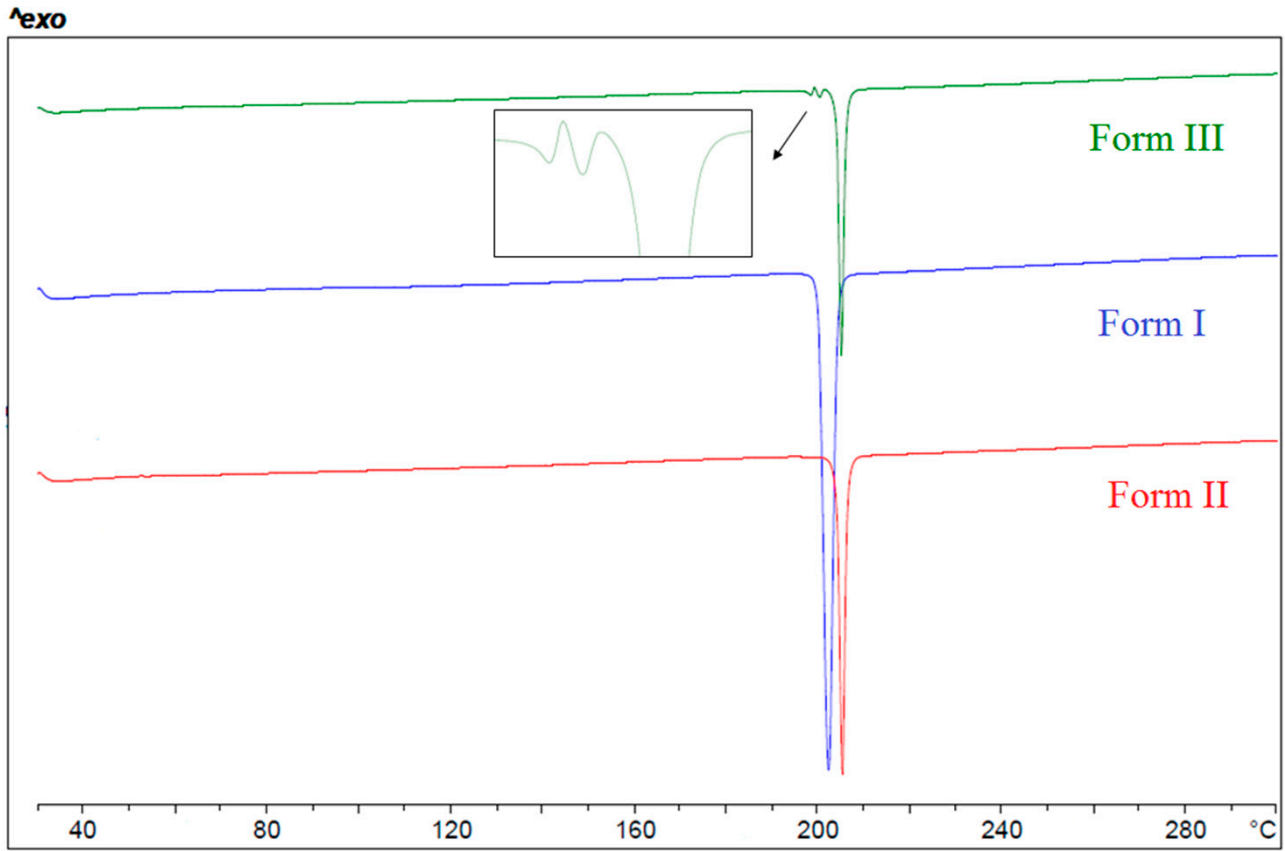

Figure 2. DSC analysis of the different anhydrous forms of BL, showing the melting of form I at $200{ }^{\circ} \mathrm{C}$, form II at $202^{\circ} \mathrm{C}$ and form III at $197^{\circ} \mathrm{C}$ followed by simultaneous crystallization and melting of form I and subsequent crystallization and melting of form II.

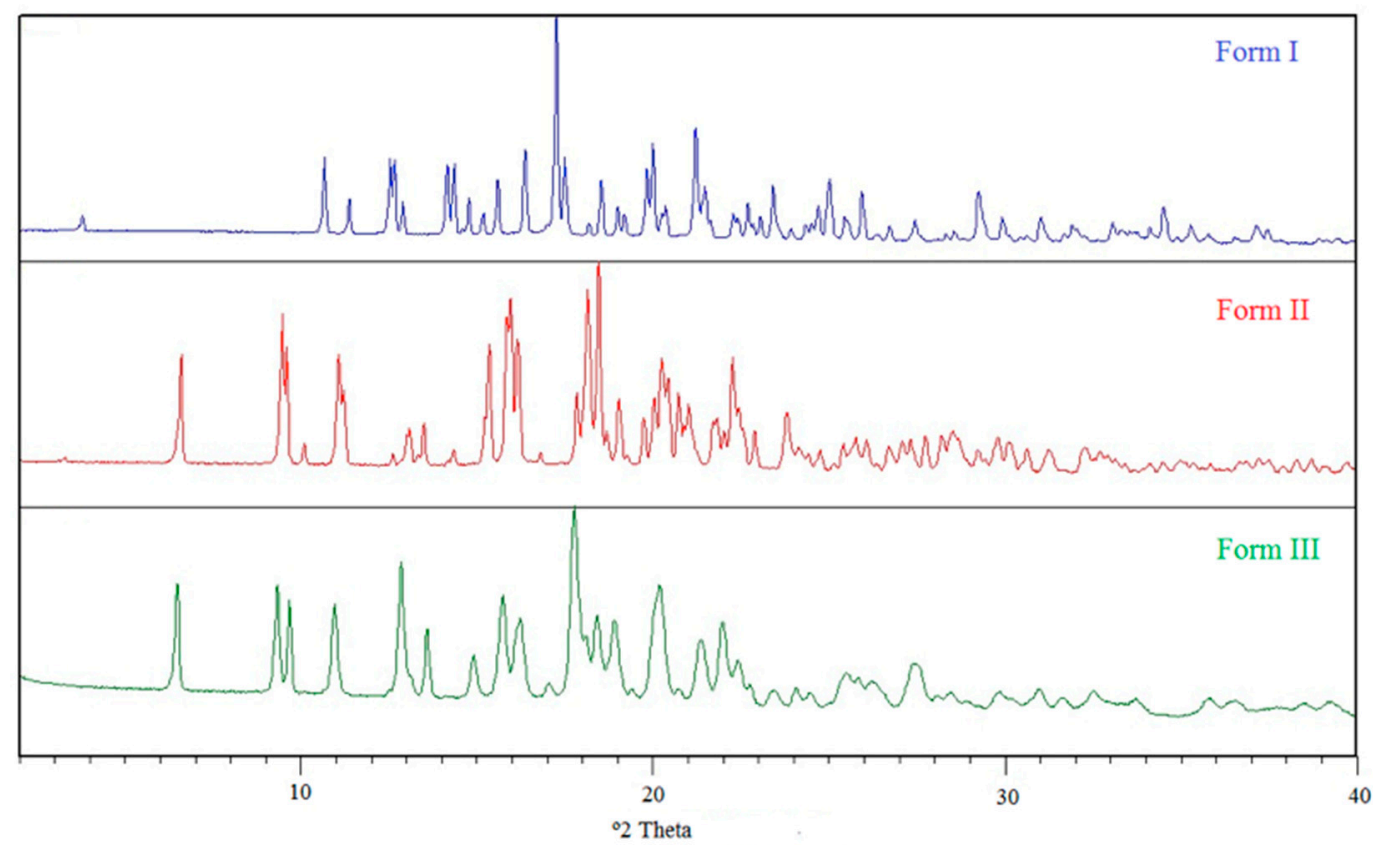

Figure 3. PXRD patterns of the different anhydrous forms of BL.

\subsection{Relative Thermodynamic Stability among the Anhydrous Solid Forms}

Form I was known to be the most stable form at r.t., and slurries of mixtures of I + II and I + III resulted in complete transformation into form I. The main question to solve is whether two polymorphs are monotropically (one form is more stable than the other at any temperature) or enantiotropically (a transition temperature exists, below and above which the stability order is reversed) related, and for an enantiotropic system, where transition temperature lies.

Table 1 summarizes the physicochemical data of the three modifications of BL obtained from the thermal analysis experiments. According to the Heat of Fusion Rule of Burger 
and Ramberger [22], forms I and II are enantiotropically related due to the higher enthalpy of fusion and lower melting point of form I. An estimation of the transition temperature between an enantiotropic pair of polymorphs can be done by using the treatment of Yu [23]. This method uses the temperatures and enthalpies of fusion to calculate the Gibbs free energy difference at the melting temperature of the lower melting form and to extrapolate to other temperatures.

$$
T_{t r s}=\frac{\Delta H_{f u s, 2}-\Delta H_{f u s, 1}+k \Delta H_{f u s, 1}\left(T_{f u s, 1}-T_{f u s, 2}\right)}{\frac{\Delta H_{f u s, 2}}{T_{f u s, 2}}-\frac{\Delta H_{f u s, 1}}{T_{f u s, 1}}+k \Delta H_{f u s, 1} \ln \left(\frac{T_{f u s, 1}}{T_{f u s, 2}}\right)}
$$

Table 1. Physicochemical data of anhydrous forms of BL.

\begin{tabular}{ccc}
\hline & $\mathbf{T}_{\text {fus }}\left({ }^{\circ} \mathbf{C}\right)$ & $\Delta \mathbf{H}_{\text {fus }}(\mathbf{J} / \mathbf{g})$ \\
\hline Form I & 200 & 119.9 \\
Form II & 202 & 118.2 \\
Form III & 197 & - \\
\hline
\end{tabular}

A value of 0.003 was used for the factor $k$, which was empirically determined and allows a good approximation of the heat capacity differences in the majority of cases [23]. Using this equation, we calculated a value of $137^{\circ} \mathrm{C}$ for the I/II pair.

It was not possible to obtain the value of the enthalpy of fusion of form III as this form transformed while heating in the DSC analysis. Regarding the relative thermodynamic stability between the pair I/III, form I is more stable than III at r.t., being this last one the lower melting form. Therefore, forms I and III must be monotropically related at least from r.t., being form I the most stable one.

As for the pair II/III, without knowing the enthalpy of fusion of form III, it was not possible to use the Heat of Fusion Rule of Burger and Ramberger; therefore, we applied the solvent mediated transformation method [24]. This method is based on the relationship between solubility and stability of crystal forms, i.e., the less stable form will also be the most soluble at given conditions of temperature and pressure. If crystals of both forms are mixed with a saturated solution of the product, the most stable form will grow at the expense of the less stable one. Thus, a mixture of the two modifications was stirred in ethanol at r.t., and after one hour, pure form I was recovered. Hence, a reduction of time was required and a suspension of II and III was stirred for $15 \mathrm{~min}$. Comparing the PXRD between the initial and the final mixture, a decrease in the intensity of X-ray diffraction peaks attributed to form II (compared to form III) was observed, while form I did not appear. This final mixture was suspended again in ethanol for $10 \mathrm{~min}$, and form II decreased again; however, form I began to appear in the mixture, so the transformation of II into III no longer could be studied. We concluded that form III was more stable than form II at r.t., and as III is the lower melting form, an enantiotropy relation could be inferred for the II/III pair. Without having data of the melting enthalpy of form III, it was not possible to calculate the transition temperature between II and III.

Energy diagrams such as those proposed by Burger and Ramberger [22] give considerable insight into polymorphic systems. Based on physicochemical and solvent mediated transformations data, a semi-schematic energy/temperature diagram was constructed in order to display the thermodynamic relationship of the anhydrous polymorphs at different temperatures (Figure 4). 


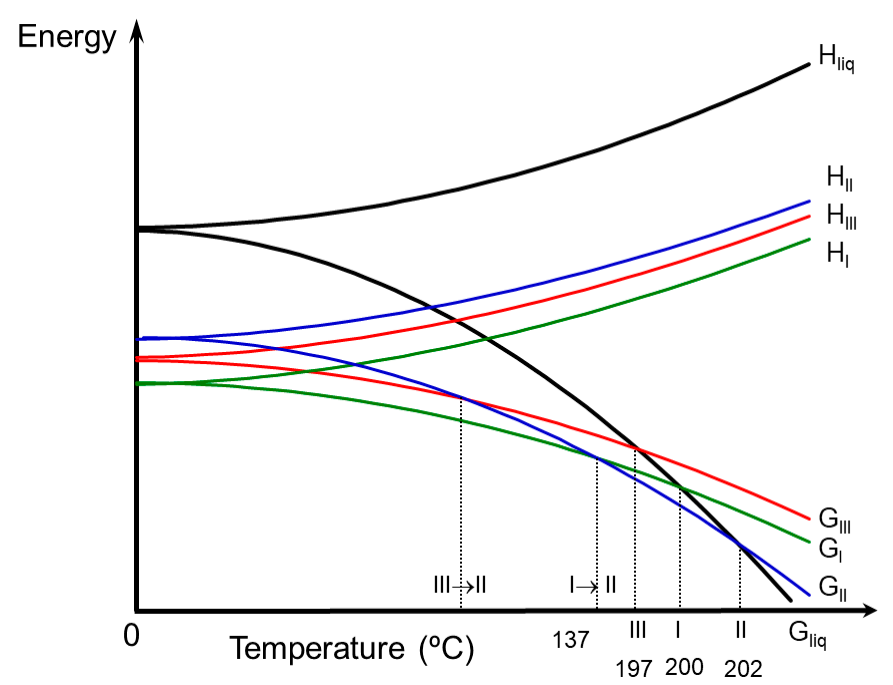

Figure 4. Semi-schematic energy/temperature diagram of anhydrous forms of BL.

\subsection{Chloroform Solvates}

During the preparation of the anhydrates, new forms were detected when chloroform was used. Therefore, a solid from screening starting from anhydrous form I and form III has been performed in chloroform as solvent. Different thermodynamic and kinetic conditions have been applied, and several antisolvents have been used. Only one chloroform solvate was identified by PXRD, and it has been fully characterized ( $\left.\mathrm{S}_{\mathrm{CHCl3}-\mathrm{H} 2 \mathrm{O}}\right)$. Its DSC analysis (Figure 5) shows a first wide endothermic phenomenon overlapped with an endothermic phenomenon at $77^{\circ} \mathrm{C}$, which could be attributed to the evaporation of the solvent and the melting of the solvate taking place simultaneously. Thermal desolvation is a complex process in which the melting, release of solvent vapor and crystallization of a new phase may occur simultaneously. Next, a low intensity phenomenon is observed at $198{ }^{\circ} \mathrm{C}$ which could be attributed to the melting of form III, followed by the melting of form II at $203^{\circ} \mathrm{C}$. Its TGA analysis shows a weight loss of $19.4 \%$ from 32 to $100{ }^{\circ} \mathrm{C}$ which could be attributed to 1 chloroform molecule and $1 \mathrm{H}_{2} \mathrm{O}$ molecule (theoretical weight loss of $22.9 \%$ ).

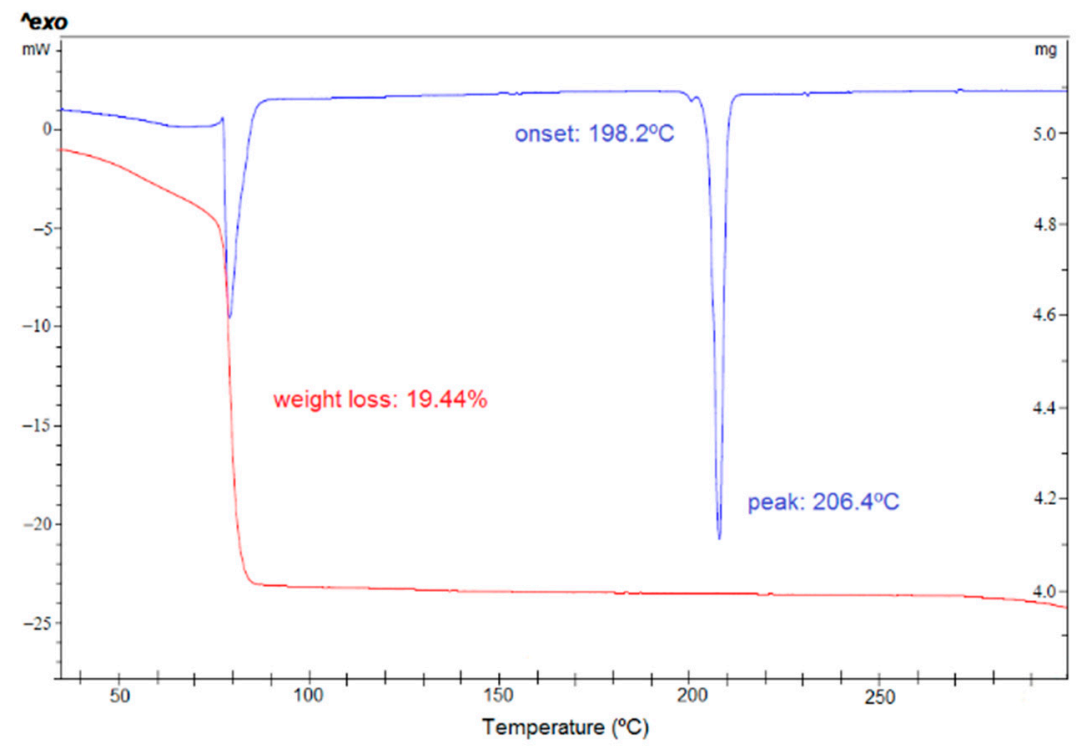

Figure 5. DSC (blue) and TGA (red) of form $\mathrm{S}_{\mathrm{CHCl3}-\mathrm{H} 2 \mathrm{O}}$.

Temperature variable powder $\mathrm{X}$-ray diffraction of form $\mathrm{S}_{\mathrm{CHC13}-\mathrm{H} 2 \mathrm{O}}$ has been performed in synchrotron Alba. In Figure 6, we can appreciate the diffractogram of $\mathrm{S}_{\mathrm{CHCl3}-\mathrm{H} 2 \mathrm{O}}$ which is stable until $74{ }^{\circ} \mathrm{C}$ and from this temperature, some new peaks corresponding to form 
III begin to appear, while characteristic peaks of $\mathrm{S}_{\mathrm{CHC13}-\mathrm{H} 2 \mathrm{O}}$ disappear. Form $\mathrm{S}_{\mathrm{CHCl3}-\mathrm{H} 2 \mathrm{O}}$ progressively transforms into form III while increasing temperature until $85^{\circ} \mathrm{C}$.

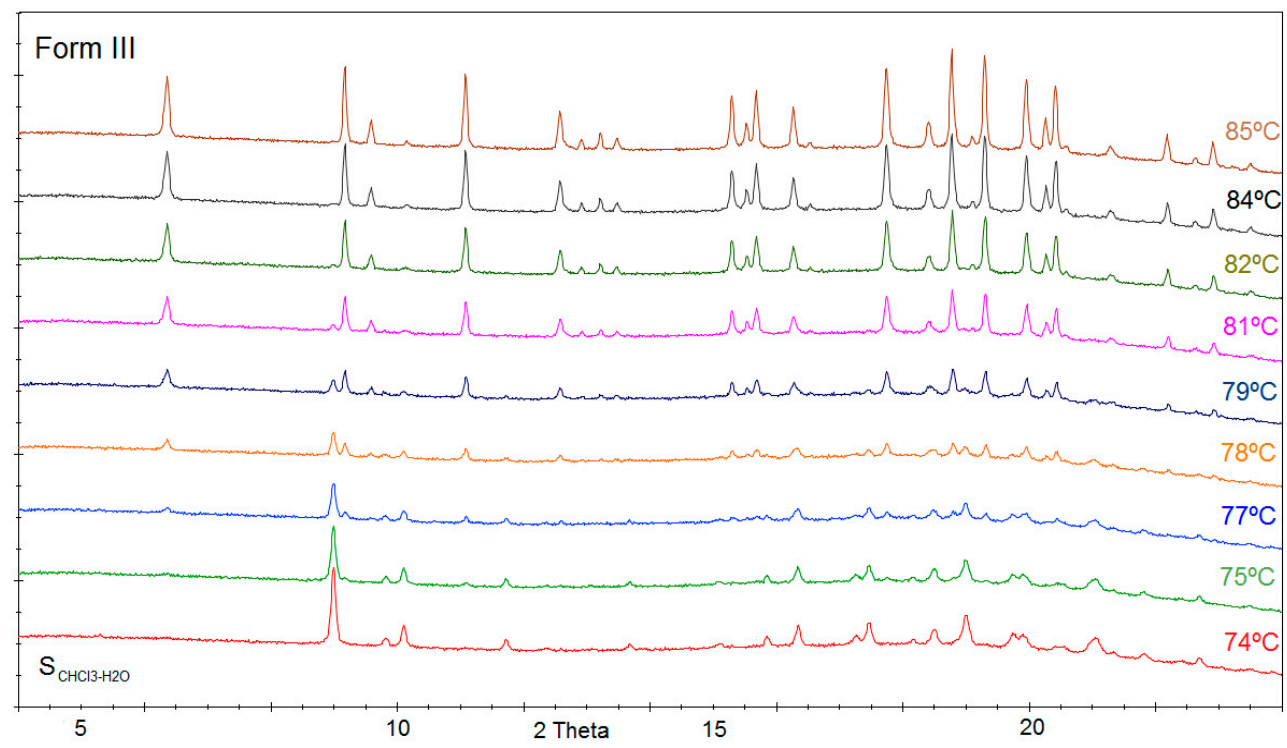

Figure 6. Temperature variable PXRD of $\mathrm{S}_{\mathrm{CHCl} 3-\mathrm{H} 2 \mathrm{O}}$ showing its transformation into form III.

In addition, different experiments in chloroform (vapor diffusion, slow cool crystallizations) were performed in order to get a single crystal of $\mathrm{S}_{\mathrm{CHCl} 3-\mathrm{H} 2 \mathrm{O}}$. Curiously, we always obtained under different conditions good quality crystals of a new solid form, as the PXRD calculated from its crystal structure solved did not match with any of the previously known forms. As shown by its crystal structure determination, this form consisted of one molecule of $\mathrm{BL}$, one molecule of water and three chloroform molecules, so it was

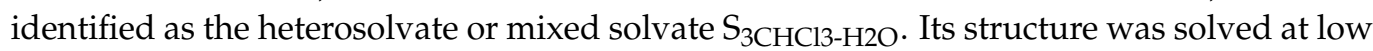
temperature, and when leaving the crystal to reach r.t., the crystal collapsed, and it was impossible to measure it at ambient conditions. The presence of opaque crystals indicated that the product had transformed opaque due to pseudomorphosis. Therefore, the single crystals (which darkened immediately at r.t.) were analyzed by PXRD at r.t., and their diffractogram matched with the one of form $\mathrm{S}_{\mathrm{CHCl} 3-\mathrm{H} 2 \mathrm{O}}$. Therefore, the new form obtained at low temperature in SCXRD is a precursor of $\mathrm{S}_{\mathrm{CHCl} 3-\mathrm{H} 2 \mathrm{O}}$ by losing 2 chloroform molecules from its crystal structure. Indeed, form $\mathrm{S}_{3 \mathrm{CHCl}} \mathrm{H}-\mathrm{H} 2 \mathrm{O}$ is the one which is always obtained in chloroform solutions, and it immediately transforms into $\mathrm{S}_{\mathrm{CHCl} 3-\mathrm{H} 2 \mathrm{O}}$ when removing it from the mother liquor, preventing its detailed characterization by other methods. The instability of this new identified solvate of BL means that we cannot exclude the discovery of other labile solvate forms. Highly unstable solvates are more common among small organic molecules than is generally believed [25].

The discovery of those mixed chloroform-water solvates led us to conduct a screening in anhydrous chloroform too. A new chloroform solvate $\mathrm{S}_{\mathrm{CHCl}}$ was discovered; however, it was only obtained as single crystal. Again, this solvate darkened when removing it from the mother liquor at r.t., and it was only possible to solve its structure at low temperature. The analysis of the corresponding PXRD at r.t. resulted in $\mathrm{S}_{\mathrm{CHCl3}-\mathrm{H} 2 \mathrm{O}}$, revealing that $\mathrm{S}_{\mathrm{CHCl} 3}$ transformed also into $\mathrm{S}_{\mathrm{CHCl3}-\mathrm{H} 2 \mathrm{O}}$, but in this case by incorporating one water molecule in its crystal structure. Figure 7 shows the PXRD diffractograms of the three chloroform solvates of BL. 


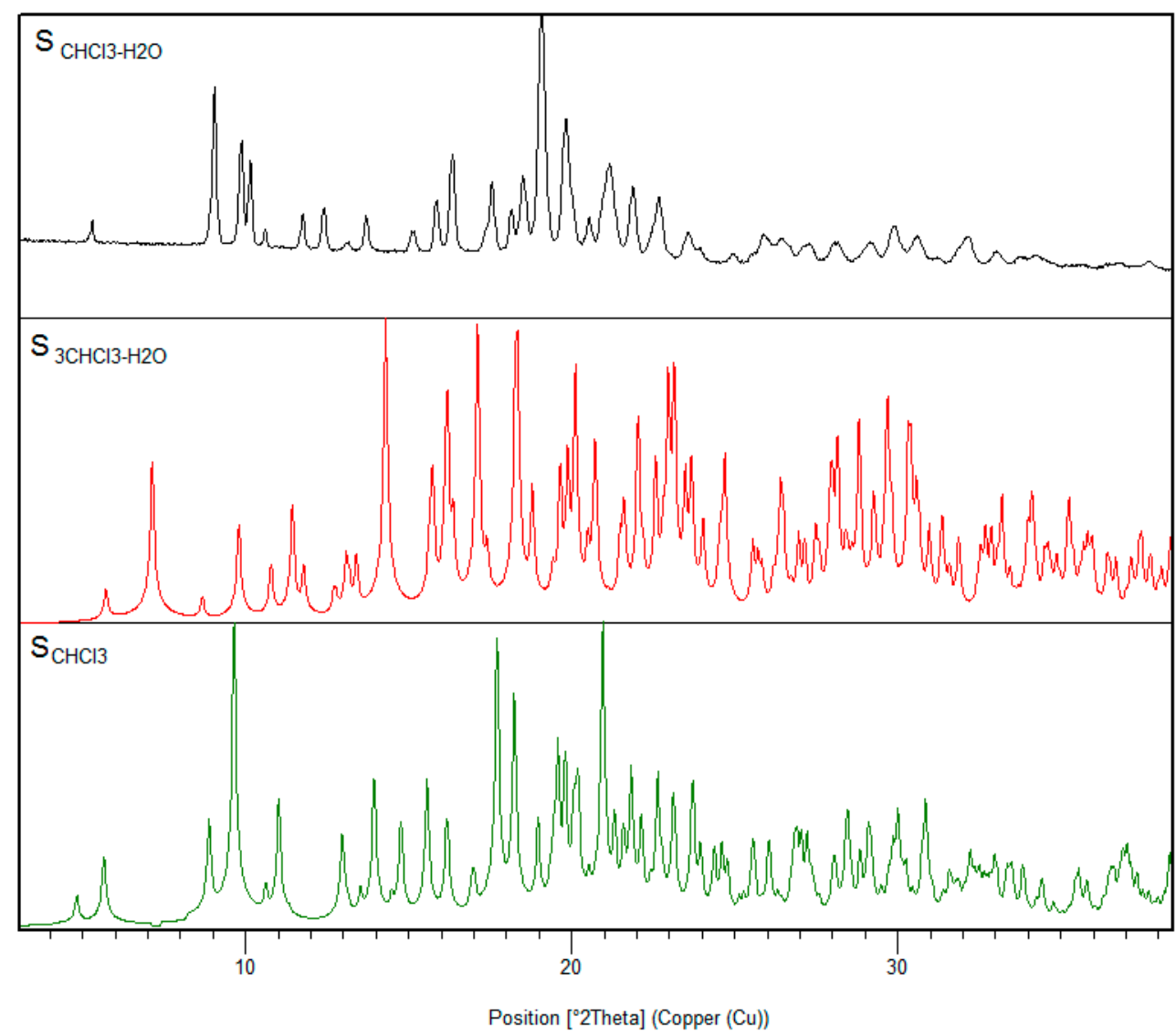

Figure 7. PXRD comparison among the different chloroform solvates.

Thus, we can conclude that both chloroform solvates $\mathrm{S}_{3 \mathrm{CHCl} 3-\mathrm{H} 2 \mathrm{O}}$ and $\mathrm{S}_{\mathrm{CHCl}}$ are only stable at low temperature or inside chloroform solutions (anhydrous in the case of $\mathrm{S}_{\mathrm{CHCl} 3}$ ) and that they transform immediately into $\mathrm{S}_{\mathrm{CHCl3}-\mathrm{H} 2 \mathrm{O}}$ at r.t. Both forms can be best described as transient or elusive phases as they become unstable after removal from the mother liquor. There are other examples in the literature of these labile solvates, and their existence needs to be known and considered [26]. Solvates that desolvate readily as soon as they are removed from the mother liquor can easily be overlooked in solid form screenings and wrong conclusions concerning the solvent effects on the nucleation of individual phases may result [27].

\subsection{Stability and Interrelation Pathways among the Solvates and Anhydrous Forms}

The stability of $\mathrm{S}_{\mathrm{CHCl} 3-\mathrm{H} 2 \mathrm{O}}$ in front of temperature was studied when heating it in a DSC experiment, and it was observed that from $50{ }^{\circ} \mathrm{C}$ this solvate was no longer stable and began to transform into form III (Figure 5).

The stability of $\mathrm{S}_{\mathrm{CHCl} 3-\mathrm{H} 2 \mathrm{O}}$ in front of relative humidity has been studied at r.t. by placing this sample inside desiccators containing different saturated salt solutions which create different $\mathrm{RH}$ conditions. From $0 \%$ to $43 \% \mathrm{RH}, \mathrm{S}_{\mathrm{CHCl} 3-\mathrm{H} 2 \mathrm{O}}$ was stable at least during one month. At $57-75 \%$ RH, this form began to transform into form III after one month.

In addition, the stabilities of forms I, III and $\mathrm{S}_{\mathrm{CHCl} 3-\mathrm{H} 2 \mathrm{O}}$ were studied under different chloroform atmospheres. While the relative thermodynamic stability of polymorphs depends only on the temperature at constant pressure, the stability relationship between a solvate and a non-solvated form, or two solvates, depends not only on the temperature but also on the activity of the solvent at constant pressure. To obtain different relative solvent vapor pressures, chloroform solutions in DMF were prepared according to the Raoult's law [28]:

$$
x=\frac{p}{p_{0}}=\frac{n}{n_{0}+n}
$$


where $x$ is the solvent mole fraction in solution; $p_{0}$ is the vapor pressure of pure solvent; $p$ is the partial solvent vapor pressure over the solution; $n$ represents the amount of used solvent in the solution; $n_{0}$ is the moles of DMF in the solution. The samples were placed in desiccators with the prepared solutions of different partial pressures of chloroform. At $0-40 \% \mathrm{CHCl}_{3}$, forms I and III remain invariable while $\mathrm{S}_{\mathrm{CHCl3}-\mathrm{H} 2 \mathrm{O}}$ transformed into $\mathrm{II}+$ traces of $\mathrm{I}$ at $0 \%$ and into I at $20-40 \% \mathrm{CHCl}_{3}$. While increasing chloroform proportion to $60-80 \%$, form I did not change; form III transformed into a mixture of III+I, and $\mathrm{S}_{\mathrm{CHC13}-\mathrm{H} 2 \mathrm{O}}$ remained invariable. Under $100 \%$ chloroform atmosphere, both anhydrous forms transformed into $\mathrm{S}_{\mathrm{CHCl} 3-\mathrm{H} 2 \mathrm{O}}$.

Curiously, at r.t. under 0\% $\mathrm{RH}, \mathrm{S}_{\mathrm{CHCl} 3-\mathrm{H} 2 \mathrm{O}}$ does not desolvate, while under $100 \% \mathrm{DMF}$ atmosphere, mixture of II+traces of I is obtained.

The information obtained during the solid form screening and the study of the temperature- and moisture-dependent stability and interrelation pathways among the solid forms of BL has been summarized in Figure 8.

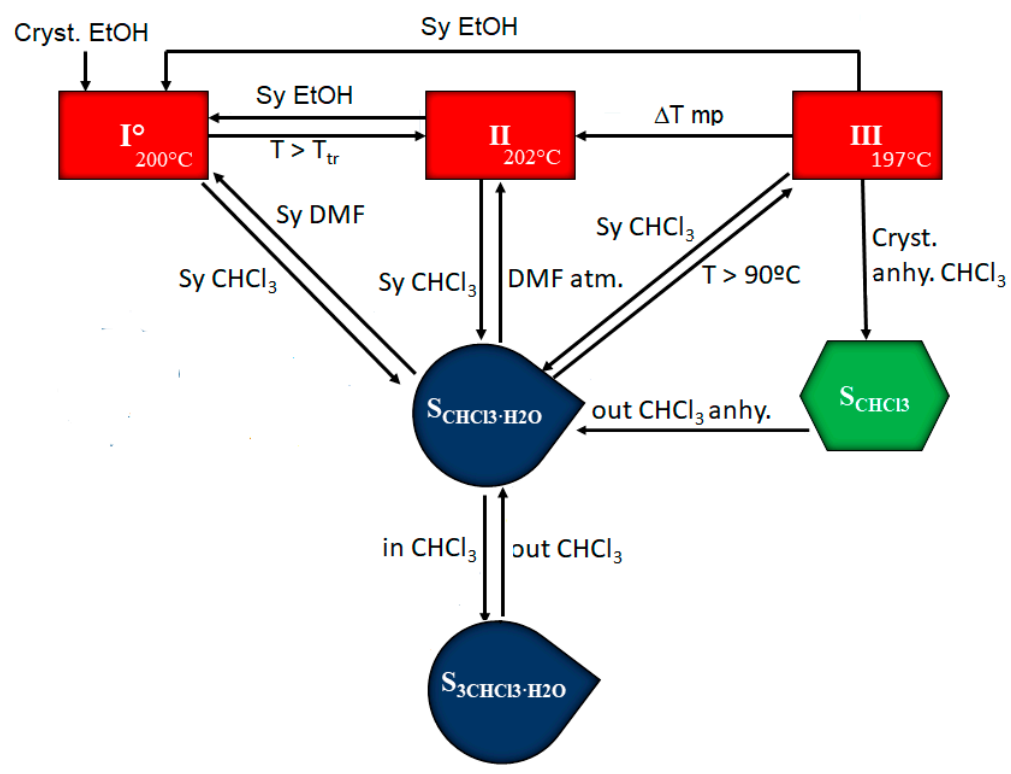

Figure 8. Pathways for phase transformations of BL solid forms as a result of heating or exposure to different solvents.

Form I is the most stable anhydrous form at r.t. which can be obtained by slurry in ethanol from the other anhydrous forms. Form II can be obtained from I and from III by increasing temperature, as it is enantiotropically related with both forms. A slurry in $\mathrm{CHCl}_{3}$ at r.t. produces the heterosolvate $\mathrm{S}_{3 \mathrm{CHCl}-\mathrm{H} 2 \mathrm{O}}$ which is transformed into $\mathrm{S}_{\mathrm{CHCl3}-\mathrm{H} 2 \mathrm{O}}$ when taken out of the solution. Heating $\mathrm{S}_{\mathrm{CHCl} 3-\mathrm{H} 2 \mathrm{O}}$ produces its desolvation and transformation into form III. On the other hand, the slurry of $\mathrm{S}_{\mathrm{CHCl3}-\mathrm{H} 2 \mathrm{O}}$ in DMF leads to form I while maintaining $\mathrm{S}_{\mathrm{CHCl} 3-\mathrm{H} 2 \mathrm{O}}$ under DMF atmosphere allows the isolation of form II in short time (form I appears later). Finally, the use of anhydrous chloroform leads to chloroform solvate $\mathrm{S}_{\mathrm{CHCl}}$ which transforms also to $\mathrm{S}_{\mathrm{CHCl} 3-\mathrm{H} 2 \mathrm{O}}$ when taken out of solution.

\subsection{Crystal Structures Analysis}

\subsubsection{Bilastine Anhydrates}

Three anhydrous polymorphs of BL were obtained. Form I was solved by single crystal $X R D$. This anhydrate crystallizes in the monoclinic space group $P 2_{1} / c$ with $Z=4$. This structure is zwitterionic as the piperidinyl $\mathrm{N}$ atom is protonated, revealing a proton transfer from the carboxylic group. For an amphoteric molecule with measured $\mathrm{p} K_{\mathrm{a}}$ values of 4.06 (carboxylic acid) and 9.43 (piperidine- $\mathrm{N}$ ), application of the $\mathrm{p} K_{\mathrm{a}}$ rule of three would suggest that proton transfer from the carboxylic acid to the piperidine- $\mathrm{N}$ is essentially complete rendering BL zwitterionic. BL molecules are linked by hydrogen bonds (distance: $1.567 \AA$ ) 
involving the carboxylate oxygen of one BL molecule and the piperidinium nitrogen of another BL in an alternated mode, forming corrugated layer structures (Figure 9). $\pi-\pi$ stackings are also observed between the benzene rings of the benzimidazoles (Figure 10). The observed lateral offset stack is $2.61 \AA$ [29], the centroid to centroid distance, $\mathrm{d}(\pi \cdots \pi)$ is $4.25 \AA$ and the interplanar distance is $3.35 \AA$.

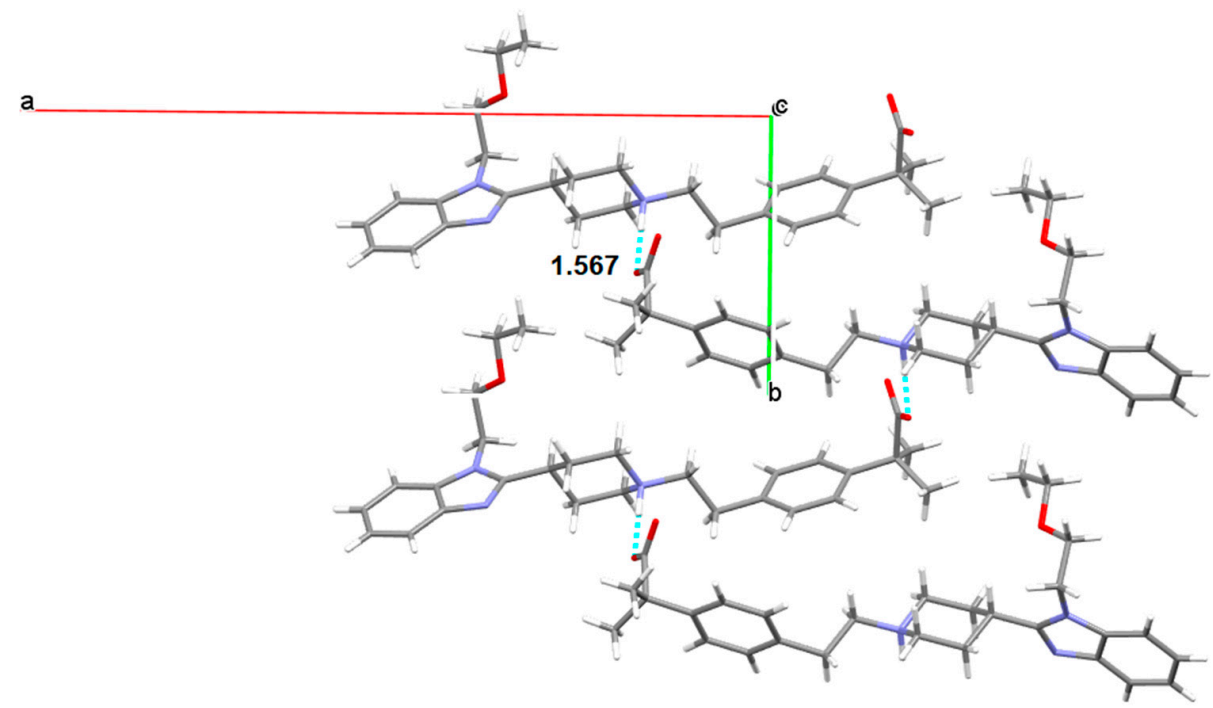

Figure 9. Carboxylate/piperidinium H-bond interactions ( $\mathrm{NH} \cdots \mathrm{O}$ distance in $\AA$ ) between $\mathrm{BL}$ molecules of Form I.

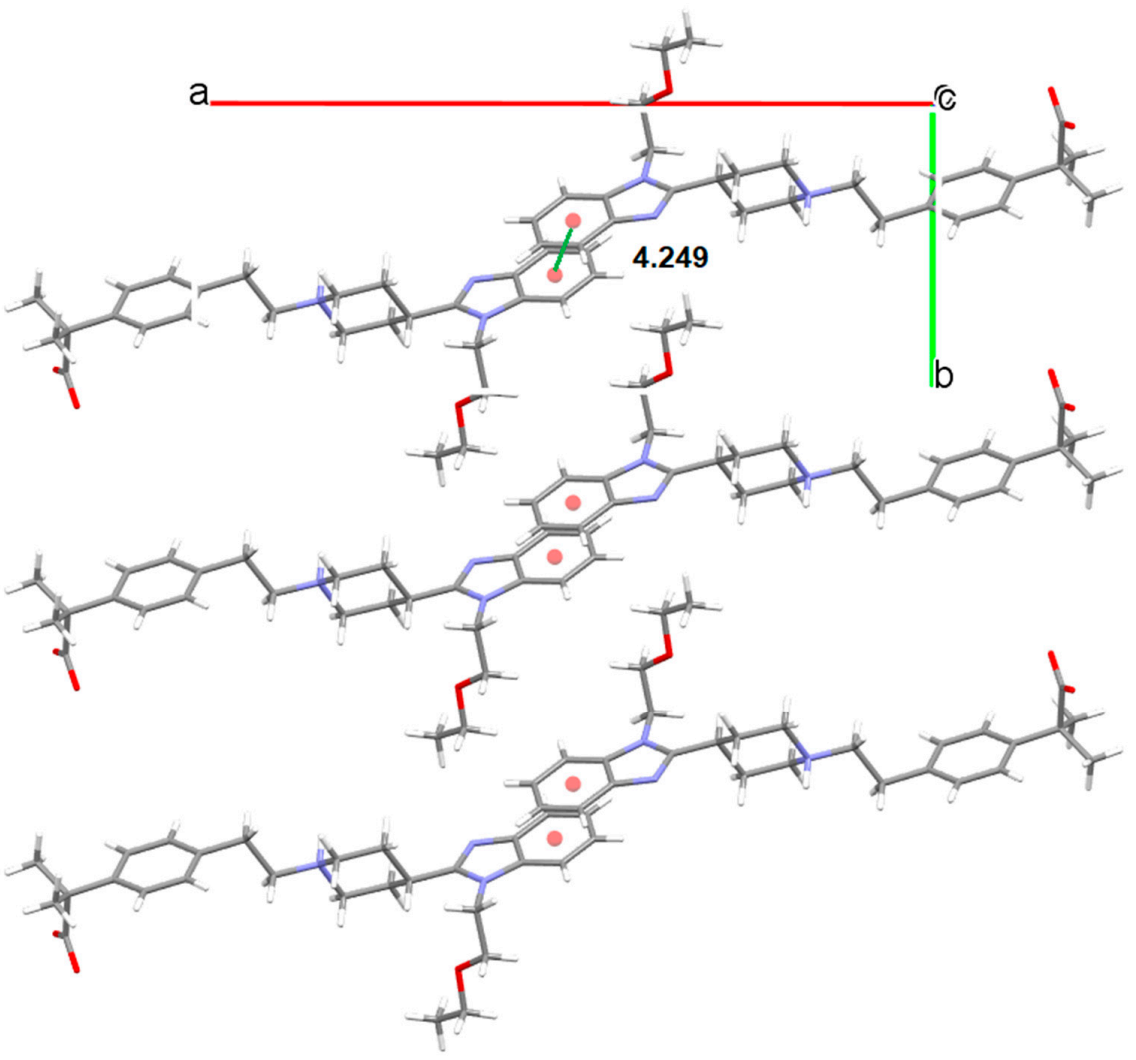

Figure 10. $\pi-\pi$ stacking (centroid-centroid distance in $\AA$ ) observed in Form I of BL.

Attempts to grow quality crystals of forms II and III were unsuccessful. Crystals of form III were grown and observed under the microscope. The extinction of a crystal is 
observed in Figure 11; however, it was impossible to cut the extreme of this crystal in order to determine its structure by SCXRD.

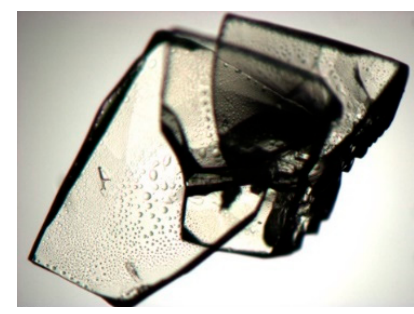

(a)

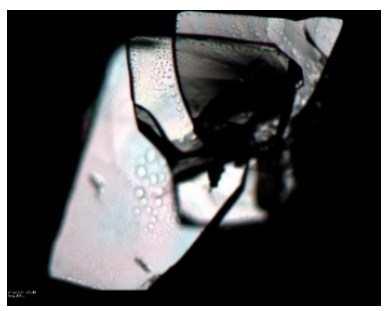

(b)

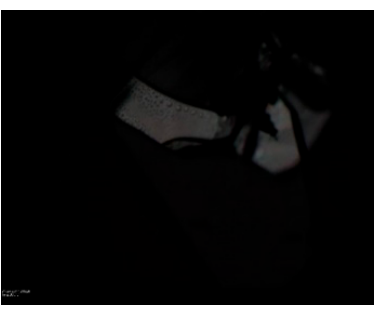

(c)

Figure 11. Photomicrographs of form III while looking under (a) unpolarized light and (b) polarized light on a circular microscope stage (c) Extinction of the crystal is observed at the optimum angle to display maximum birefringence.

Usually form III crystallized as macles, as it is shown in Figure 12.

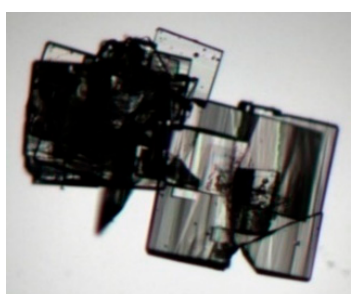

(a)

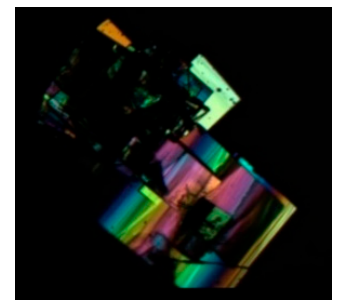

(b)

Figure 12. Photomicrographs of macles of form III observed under (a) unpolarized light and (b) polarized light microscope.

Thus, the resolution of the crystal structure of form III was achieved by using the direct space methodology using synchrotron X-ray powder diffraction data obtained in the high-resolution powder diffraction end station of the MSPD beam line in Alba. The powder diffraction pattern of form III was indexed to a monoclinic cell of about $2682 \AA^{3}$, and the space group perfectly determined to be $P 2_{1} / c$ from the systematic absences. The crystal structure was solved with the direct-space strategy TALP, and the refinement was performed by the Rietveld method. Figure 13 depicts the final Rietveld plot.

$\mathrm{P} 21 / \mathrm{c}$

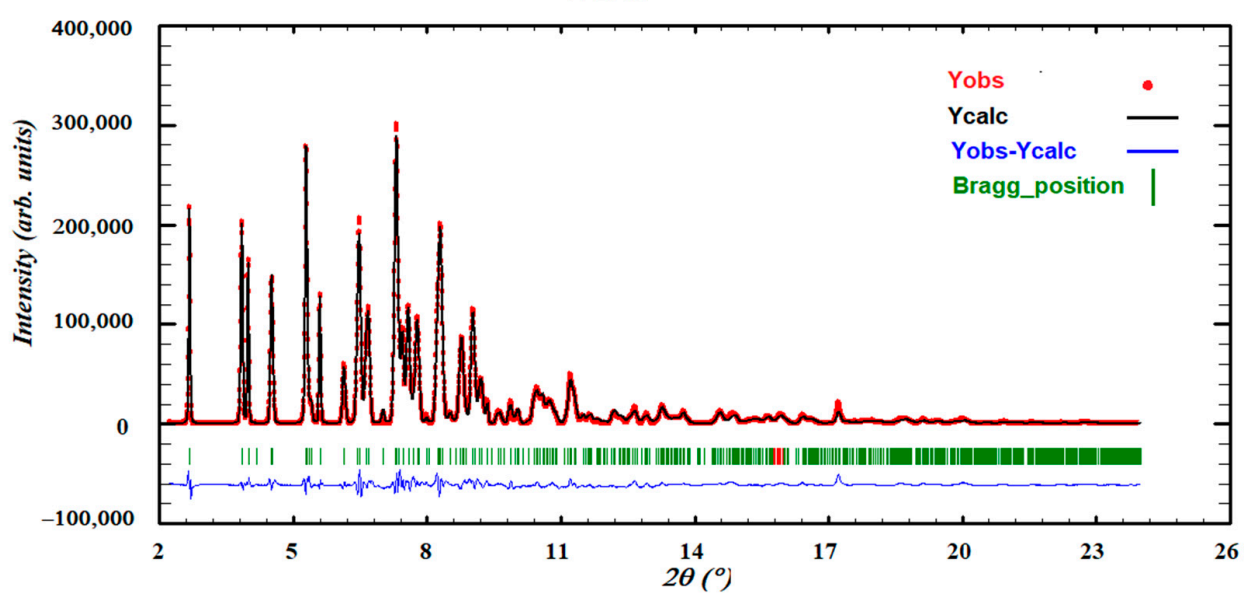

Figure 13. Final Rietveld plot for the crystal structure refinement of form III. Agreement factor: Rwp $=2.4 \%$. The plot shows the experimental powder XRD profile (red+marks), the calculated powder XRD profile (black solid line), and the difference profile (blue, lower line). Tick marks indicate peak positions. 
Form III crystallizes in the same space group $P 2_{1} / c$ with four molecules in the unit cell. BL molecules in Form III are also linked by hydrogen bonds (distance: $1.518 \AA$ ) involving the carboxylate oxygen and the piperidinium nitrogen but not in the alternated mode shown in Form I. In Form III, all BL molecules are orientated in the same way. Therefore, a remarkable difference between both polymorphs is the different orientation of the selfassembled BL chains. While in Form I BL molecules are interdigitated, in Form III, they are organized as cascade layers (Figure 14). Moreover, in Form I benzimidazoles interact via $\pi-\pi$ stacking while in Form III, the same benzimidazoles interact via $\mathrm{CH}-\pi$ with one hydrogen of the piperidinyl group (distance to the centroid: $2.93 \AA$, distance to the plane: $2.64 \AA$ and $\mathrm{H}: 1.27 \AA$ ) and with one hydrogen of the methyl group (distance to the centroid: $3.41 \AA$, distance to the plane: $2.45 \AA$ and H: $2.37 \AA$ ) (Figure 15).

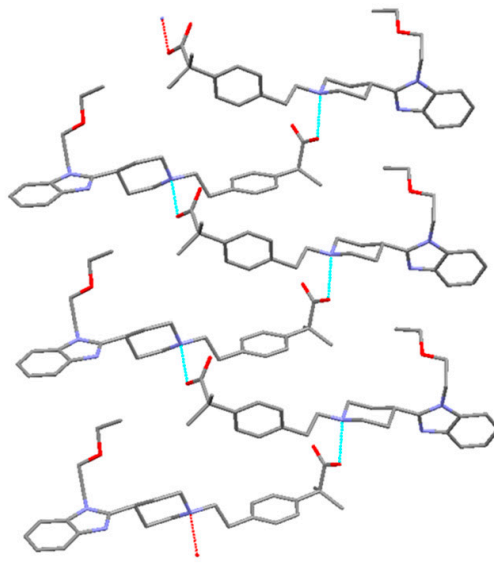

(a)

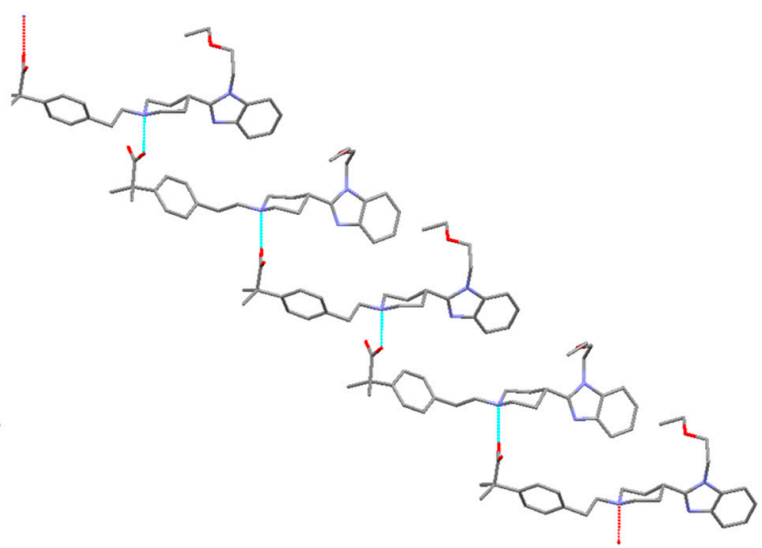

(b)

Figure 14. Comparison between the crystal structures of (a) form I (corrugated layer) and (b) form III (cascade layer) of BL.

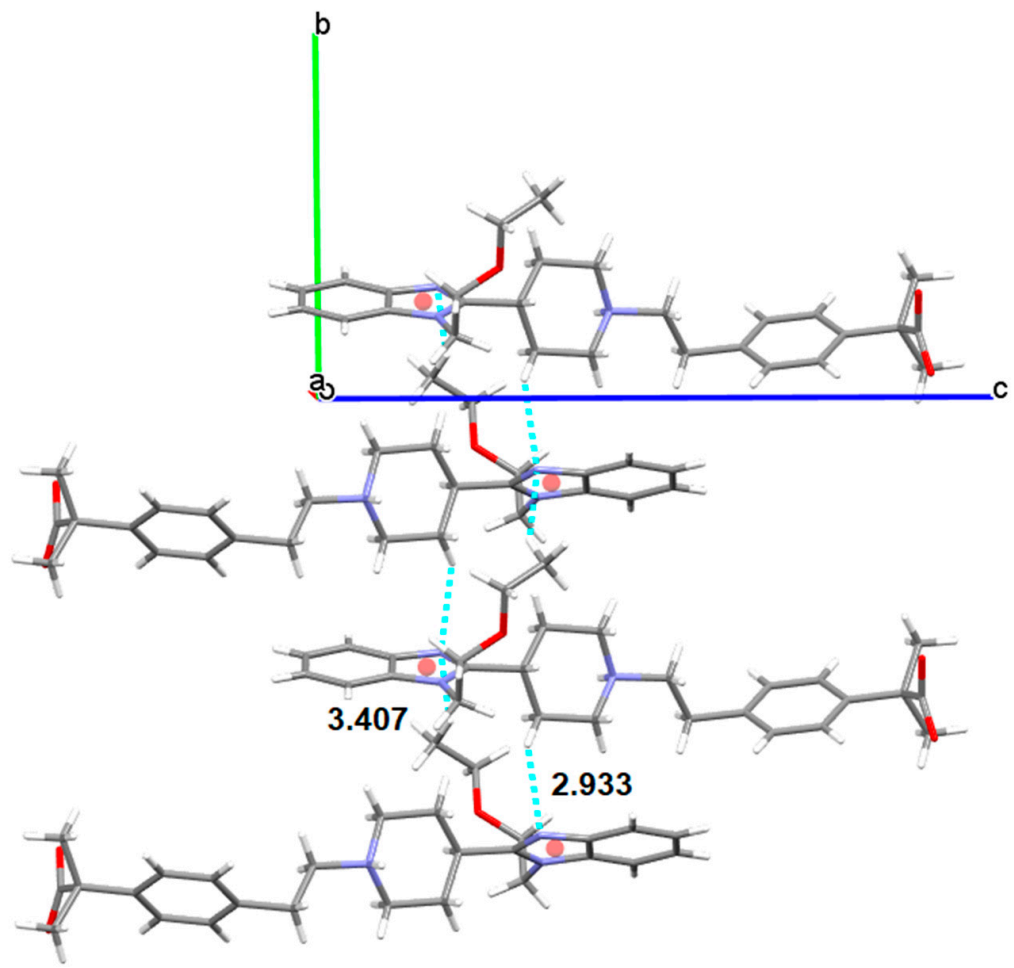

Figure 15. $\mathrm{CH}-\pi$ stacking ( $\mathrm{CH}$-centroid distances in $\AA$ ) observed in Form III of BL. 
The powder diffraction pattern of form II was indexed to a monoclinic cell $(\mathrm{a}=28.3374 \AA$, $\mathrm{b}=9.9384 \AA, \mathrm{c}=19.7547 \AA, \beta=109.2696^{\circ}$ ) of about $5251.8 \AA^{3}$ and the space group perfectly determined to be $P 2{ }_{1} / c$ from the systematic absences (Figure 16). Thus far, we have not managed to solve its crystal structure by using the direct space methodology, being an additional difficulty the presence of two different BL molecules in the asymmetric unit. Further work is still in progress.

P 21/c

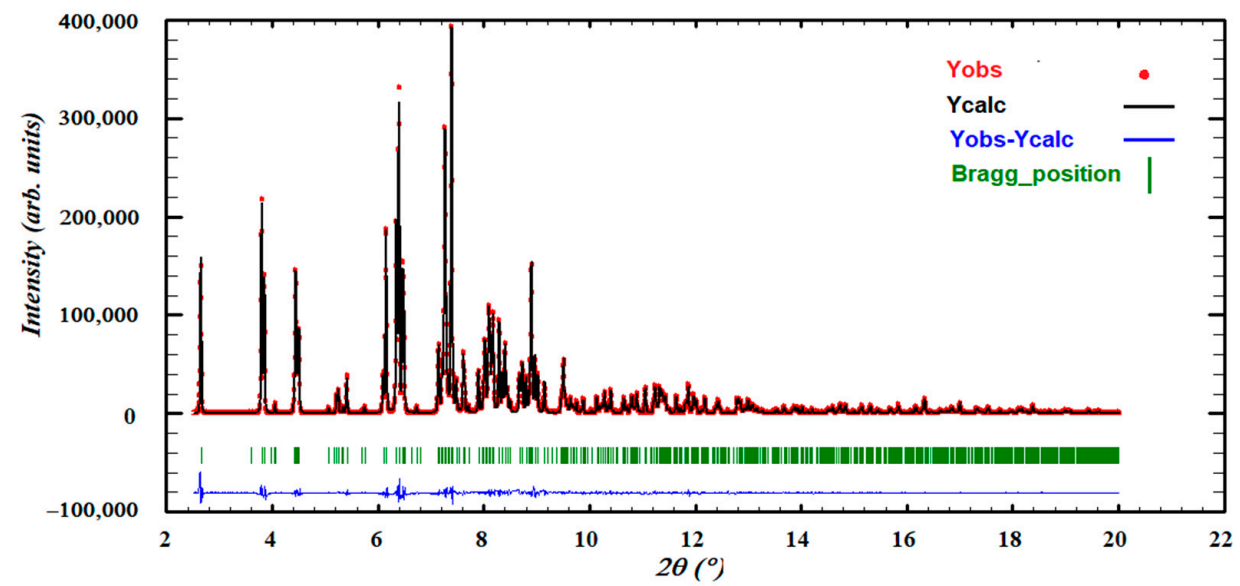

Figure 16. Pawley pattern matching plot of form II. Agreement factor: Rwp $=1.3 \%$. The plot shows the experimental powder XRD profile (red+marks), the calculated powder XRD profile (black solid line) and the difference profile (blue, lower line). Tick marks indicate peak positions.

\subsubsection{Bilastine Chloroform Solvates}

As it has been mentioned, the solvated phase $\mathrm{S}_{3 \mathrm{CHCl}-\mathrm{H} 2 \mathrm{O}}$ has resulted to be unstable, the crystals losing solvent rapidly after removal from the mother liquor and generally rendering manipulation of the material and accurate analysis of its composition impossible. The first visible signs of desolvation, such as opacification of the crystals, were observed only after seconds at r.t. However, its crystal structure has been successfully determined at $100 \mathrm{~K}$ resulting in an orthorhombic Pna $2_{1}$ cell with $\mathrm{Z}=4$. In $\mathrm{S}_{3 \mathrm{CHCl}-\mathrm{H} 2 \mathrm{O}} \mathrm{BL}$ molecules are linked by hydrogen bonds involving the carboxylate oxygen of one BL molecule and the piperidinium nitrogen of another BL in an alternated mode similar to form I, forming corrugated layer structures (Figure 17).

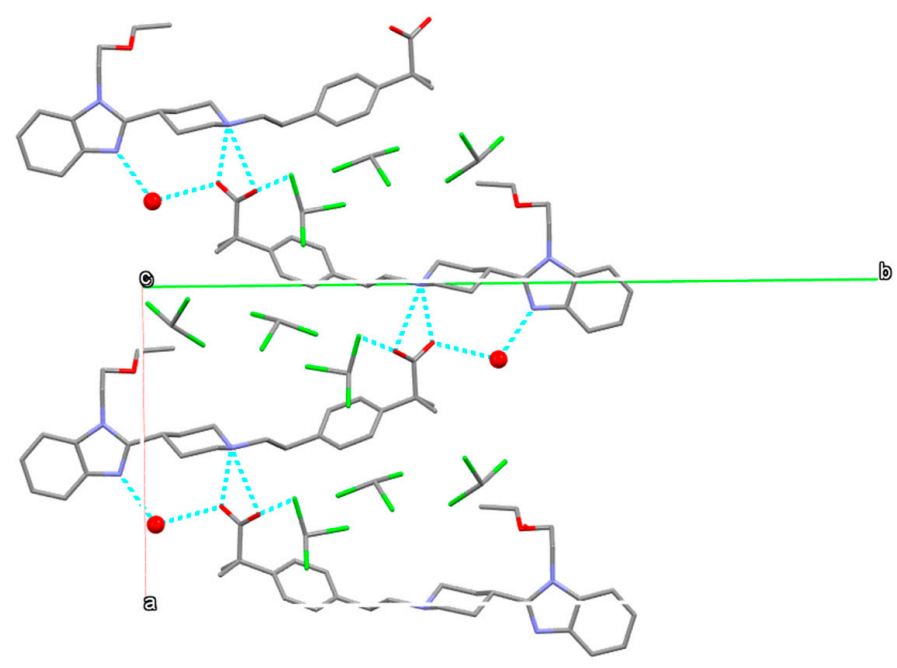

Figure 17. Carboxylate/piperidinium H-bond interactions between BL molecules observed in the crystal structure of $\mathrm{S}_{3 \mathrm{CHCl}}-\mathrm{H} 2 \mathrm{O}$. Water molecules represented by red balls. Hydrogens have been omitted for clarity. 
Water and chloroform molecules occupy voids inside the crystal structure as it is shown in Figure 18.

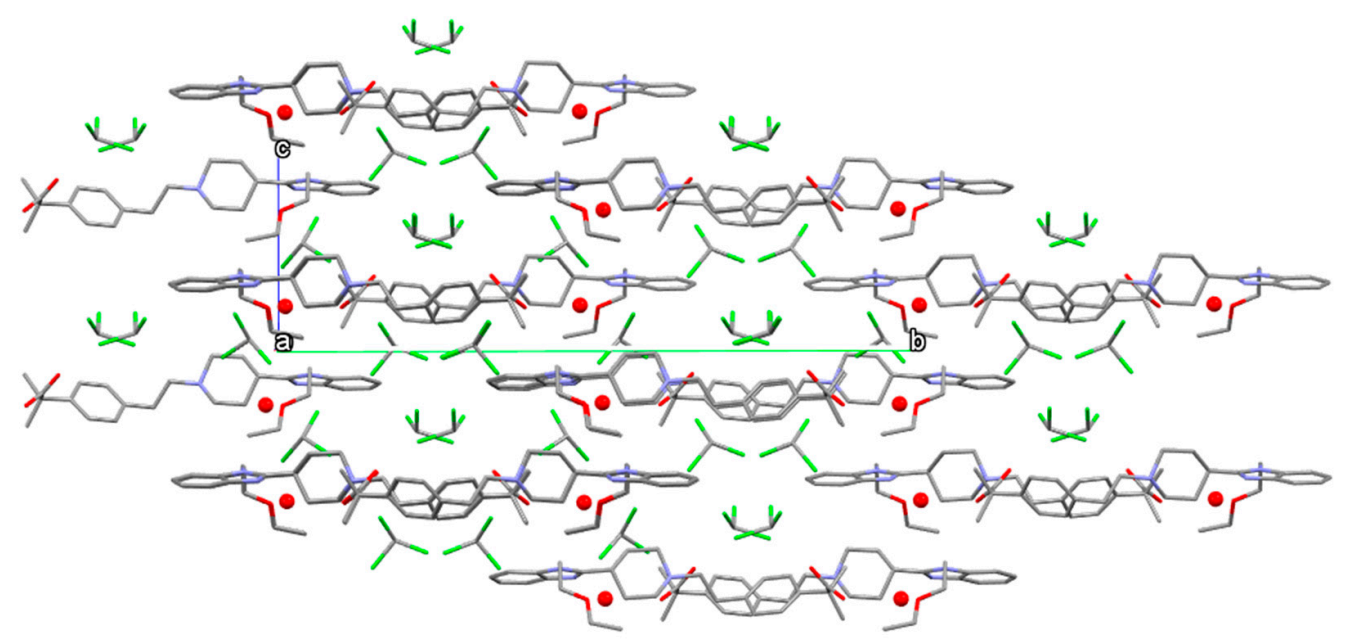

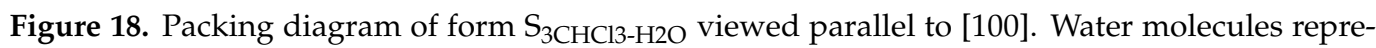
sented by red balls. Hydrogens have been omitted for clarity.

The X-ray structural analysis reveals the presence of one hydrogen-bonded water molecule as well as three hydrogen- and halogen-bonded chloroform molecules and one BL in its asymmetric unit. As shown in Figure 19, the water molecule acts as hydrogen bond donor in a DD environment, its hydrogens showing $\mathrm{H}$-bonding with the nitrogen of the benzimidazol of one BL, on one hand (distance: $2.077 \AA$ ), and with an oxygen of the carboxylate of another BL molecule, on the other hand (distance: $2.133 \AA$ ). This carboxylate oxygen is also involved in an asymmetric three-center (or bifurcated) hydrogen bond system (distances: $1.887 \AA$ and $2.452 \AA$ ) with the piperidinium of the first BL (being the structure zwitterionic), forming altogether $R^{2}{ }_{3}(11)$ and $R^{2}{ }_{1}(4)$ supramolecular heterosynthons. Moreover, one chloroform molecule interacts via halogen bond with the other oxygen of the carboxylate, being $3.139 \AA$ its $\mathrm{Cl}_{2} \mathrm{HC}-\mathrm{Cl} \cdots \mathrm{O}=\mathrm{C}$ distance, shorter than the sum of the van der Waals radii of the involved atoms. Moreover, this chloroform molecule is involved in a $\mathrm{Cl}_{3} \mathrm{C}-\mathrm{H} \cdots \mathrm{O}=\mathrm{C}$ (distance: $2.142 \AA$ ) hydrogen bond with the carboxylate and in a $\mathrm{Cl}_{2} \mathrm{HC}-\mathrm{Cl} \cdots \mathrm{Cl}-\mathrm{CHCl}_{2}$ (distance: $3.366 \AA$ ) halogen bond with a second chloroform molecule which in turn interacts with the third chloroform forming also a $\mathrm{Cl}_{2} \mathrm{HC}-\mathrm{Cl} \cdots \mathrm{Cl}^{-} \mathrm{CHCl}_{2}$ (distance: $3.322 \AA$ ) halogen bond. The second chloroform is involved also in a $\mathrm{Cl}_{3} \mathrm{C}-\mathrm{H} \cdots \pi$ (distance Ph-center: $2.354 \AA$ ) interaction with the phenyl ring of another BL and the third chloroform in turn interacts also with the water molecule via $\mathrm{Cl}_{3} \mathrm{C}-\mathrm{H} \cdots \mathrm{O}-\mathrm{H}_{2}$ (distance: $2.011 \AA$ ) hydrogen bond.

As stated, it was not possible to grow single crystals of $\mathrm{S}_{\mathrm{CHCl} 3-\mathrm{H} 2 \mathrm{O}}$ as once its precursor solvate was obtained, the crystals were not stable and two chloroform molecules were rapidly lost after removal from the mother liquor, leaving a darkened crystal. Therefore, its powder diffraction pattern was indexed to an orthorhombic cell and the space group perfectly determined to be $P n a 2_{1}$ from the systematic absences. The crystal structure was solved with the direct-space strategy TALP, and its refinement was performed by the Rietveld method. Figure 20 depicts the final Rietveld plot.

The $\mathrm{X}$-ray structural analysis of the structure of $\mathrm{S}_{\mathrm{CHCl}-\mathrm{H} 2 \mathrm{O}}$ solved from PXRD reveals the presence of one hydrogen-bonded water molecule, one hydrogen-bonded chloroform molecule and one BL in its asymmetric unit. BL molecules are also linked by hydrogen bonds involving the carboxylate oxygen of one BL molecule and the piperidinium nitrogen of another BL in an asymmetric three-center hydrogen bond system (distances: $1.731 \AA$ and $2.253 \AA$ ), with the same $R^{2}{ }_{1}(4)$ heterosynthon, forming corrugated layer structures as in $\mathrm{S}_{3 \mathrm{CHCl}-\mathrm{H} 2 \mathrm{O}}$. In this case, an interlayer interaction is accomplished by $\pi \cdots \pi$ parallel displaced phenyl stacking of the alternated BL (observed lateral offset stack: $4.66 \AA$, 
centroid to centroid distance $d(\pi \cdots \pi): 5.19 \AA$, interplanar distance: $2.29 \AA)$. Moreover, the water molecule acts as hydrogen bond donor in a D environment as only one hydrogen is involved in hydrogen-bonding (distance: $1.942 \AA$ ) with the nitrogen of the benzimidazol of one BL. Finally, the chloroform molecule is involved in a $\mathrm{Cl}_{3} \mathrm{C}-\mathrm{H} \cdots \mathrm{O}=\mathrm{C}$ (distance: $2.337 \AA$ ) hydrogen bond with the carboxylate (Figure 21).

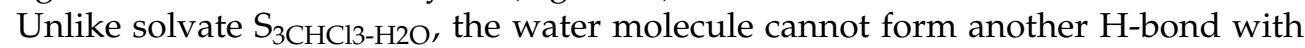
an oxygen of the carboxylate of another BL molecule as the carboxylate is not pointing towards it as it has rotated some degrees being in this case too far. The conformations of the BL molecules in both heterosolvates are compared in Figure 22, differing particularly with respect to the orientation of the carboxylate fragment.

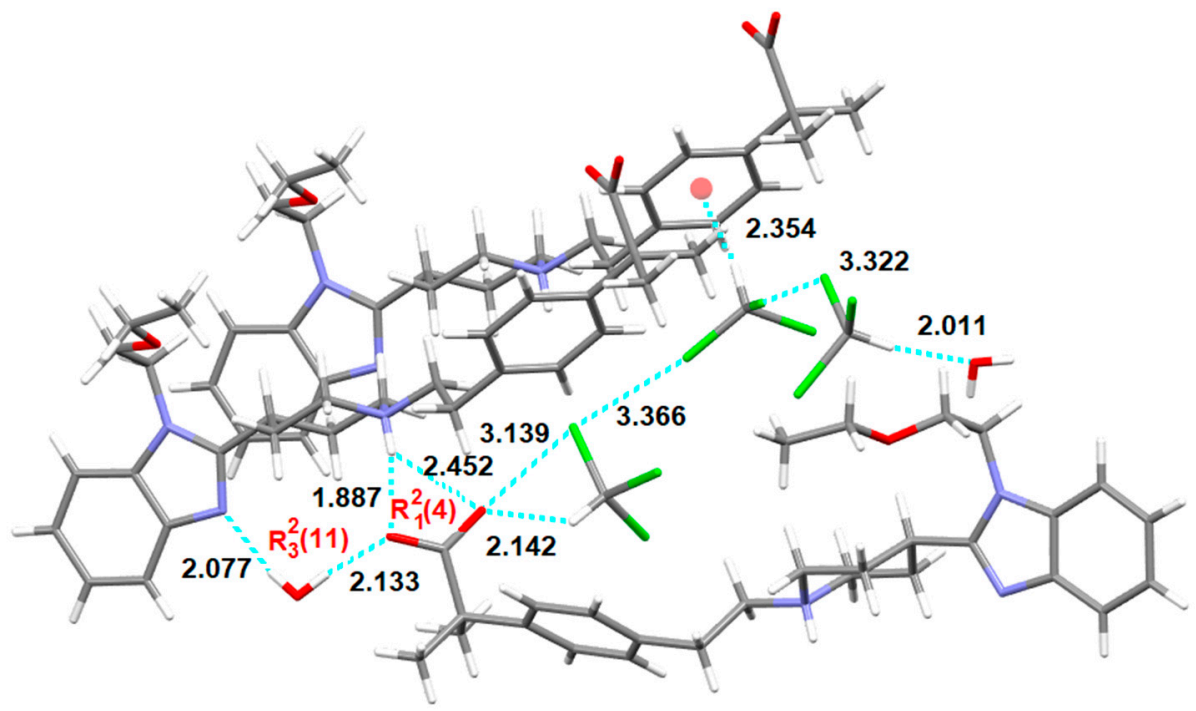

Figure 19. Intermolecular interactions (distances in $\AA$ ) observed in the crystal structure of

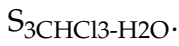

Pn a 21

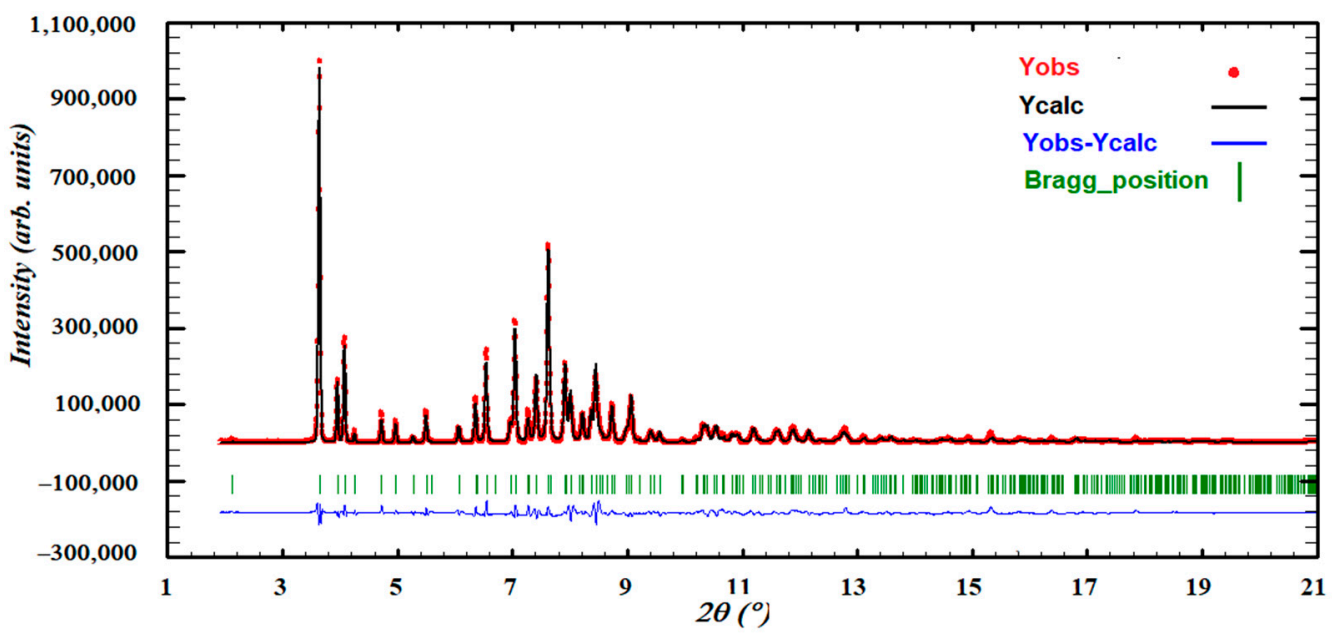

Figure 20. Final Rietveld plot for the crystal structure refinement of form $\mathrm{S}_{\mathrm{CHCl}-\mathrm{H} 2 \mathrm{O}}$. Agreement factor: $\mathrm{Rwp}=2.3 \%$. The plot shows the experimental powder XRD profile (red+marks), the calculated powder XRD profile (black solid line) and the difference profile (blue, lower line). Tick marks indicate peak positions. 


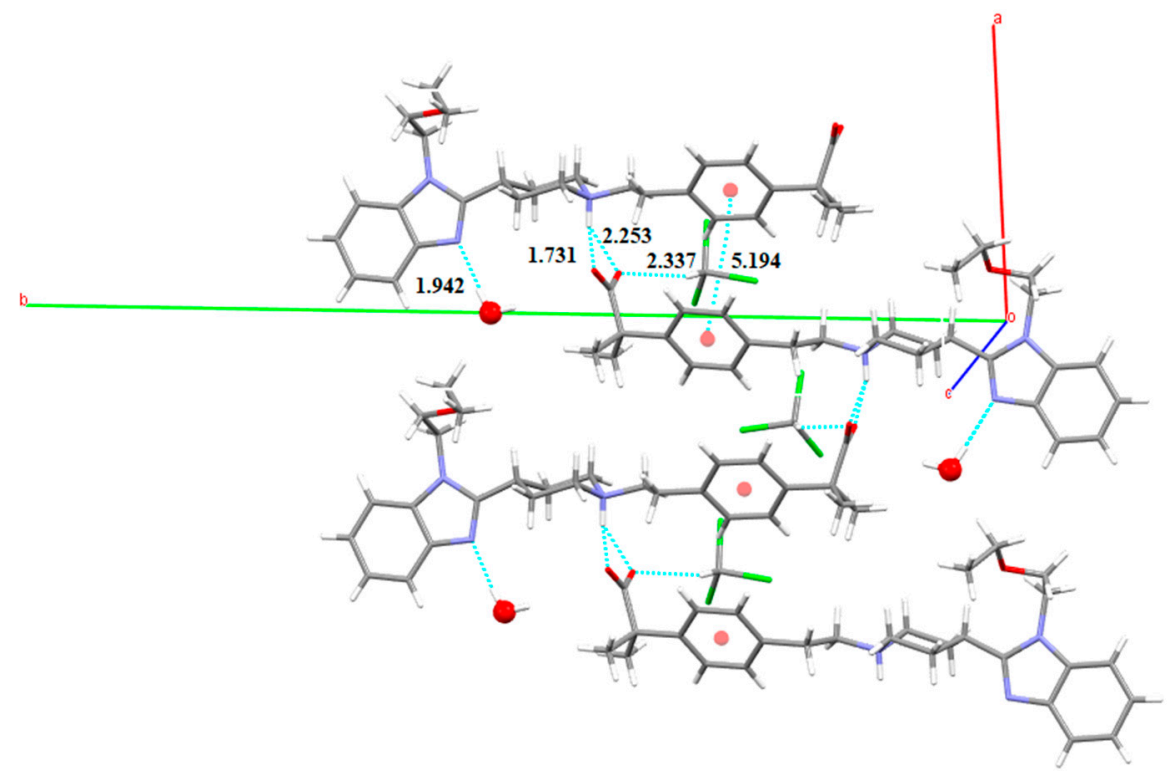

Figure 21. Intermolecular interactions (distances in $\AA$ ) observed in the crystal structure of $\mathrm{S}_{\mathrm{CHCl3}-\mathrm{H} 2 \mathrm{O}}$.

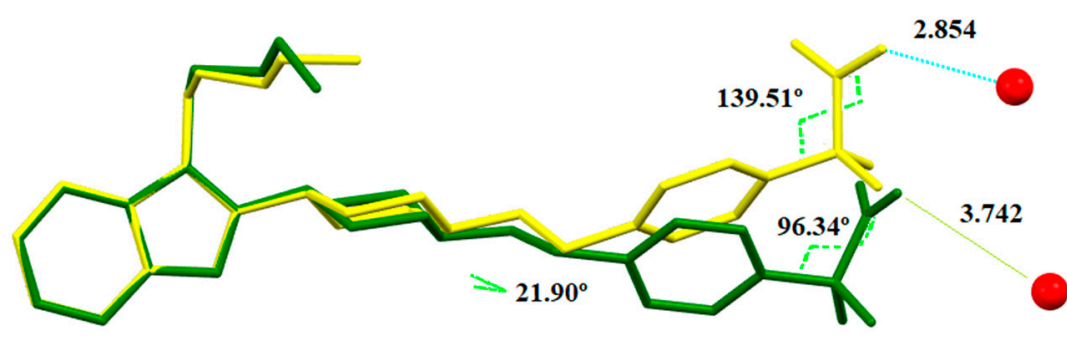

Figure 22. Overlay of BL molecules of form $\mathrm{S}_{3 \mathrm{CHCl}-\mathrm{H} 2 \mathrm{O}}$ (yellow) and $\mathrm{S}_{\mathrm{CHCl} 3-\mathrm{H} 2 \mathrm{O}}$ (green) showing that the water molecule (represented by red balls) is too far (distances in $\AA$ ) from the carboxylate of $\mathrm{S}_{\mathrm{CHCl3}-\mathrm{H} 2 \mathrm{O}}$. Hydrogen atoms are omitted for clarity.

The channeled crystal structure of solvate $\mathrm{S}_{\mathrm{CHCl}-\mathrm{H} 2 \mathrm{O}}$ is shown in Figure 23 where chloroform and water molecules occupy different channels.

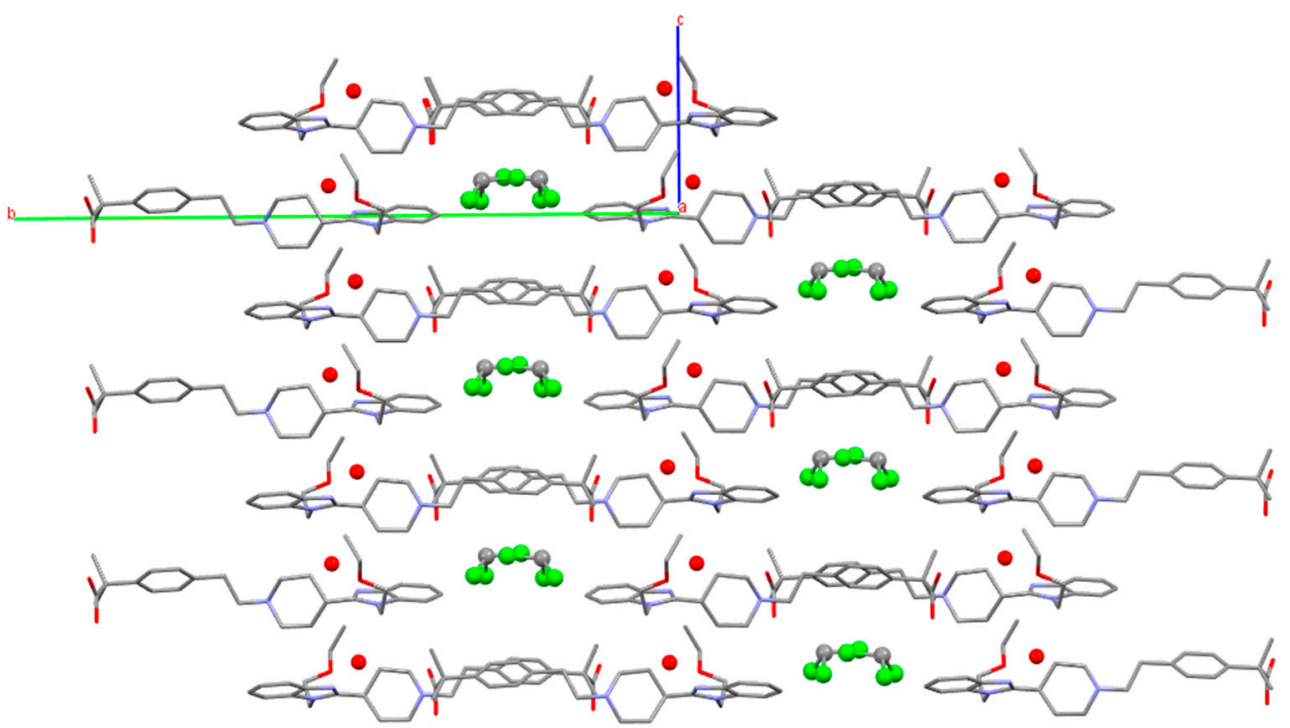

Figure 23. Crystal packing of form $\mathrm{S}_{\mathrm{CHCl} 3-\mathrm{H} 2 \mathrm{O}}$ viewed parallel to [100]. Water molecules represented by red balls. Hydrogens have been omitted for clarity. 
Finally, single crystals of $\mathrm{S}_{\mathrm{CHCl} 3}$ were grown in anhydrous chloroform. This solvate crystallizes in the monoclinic space group $P 2_{1}$ with two molecules of $\mathrm{BL}$ and two molecules of chloroform in the asymmetric unit. Again, BL molecules are linked by hydrogen bonds (distance: $1.583 \AA$ ) involving one oxygen of the carboxylate and the piperidinium $\mathrm{NH}$, forming cascade layers as in Form III (Figure 24).

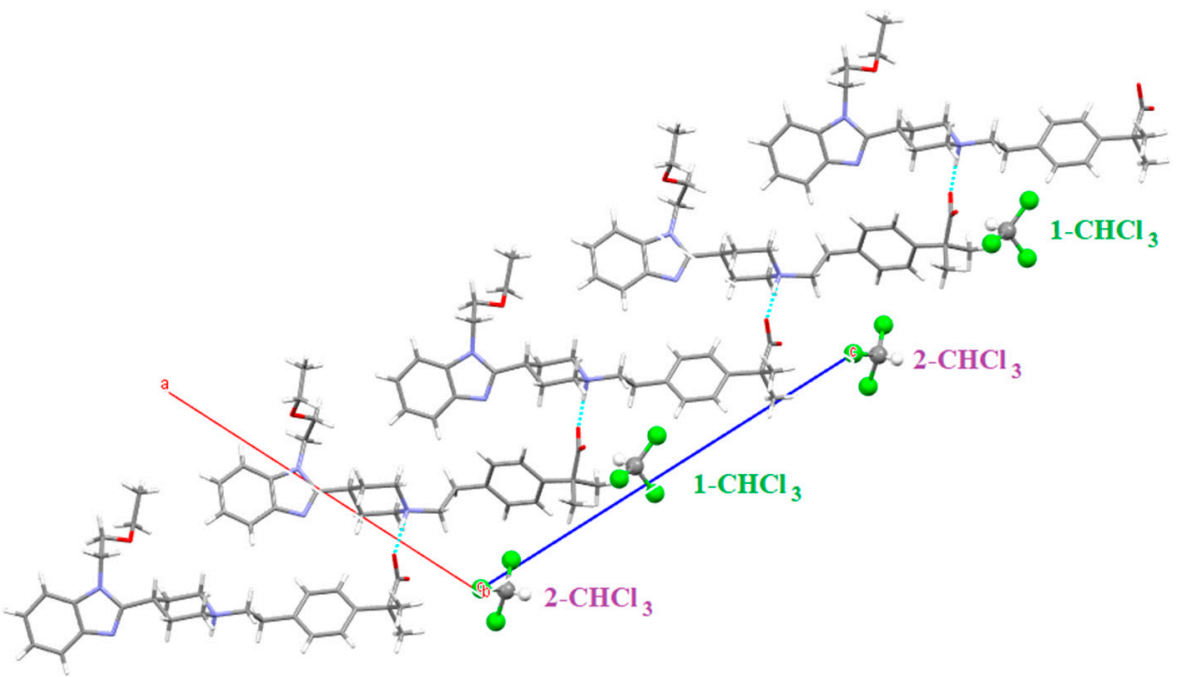

Figure 24. Hydrogen bonds between BL molecules observed in form $\mathrm{S}_{\mathrm{CHCl}}$.

There are two different chloroform molecules in this solvate: $1-\mathrm{CHCl}_{3}$ which is involved in a $\mathrm{Cl}_{3} \mathrm{C}-\mathrm{H} \cdots \mathrm{O}=\mathrm{C}$ (distance: $2.008 \AA$ ) hydrogen bond with the carboxylate of one BL and 2- $\mathrm{CHCl}_{3}$ which forms the same H-bond (distance: $2.013 \AA$ ) with the carboxylate of the other BL (Figure 25). This chloroform participates also in a $\mathrm{Cl} \cdots \pi$ interaction with the benzene ring of another BL (Cl-centroid distance: $3.683 \AA$ A, C-Cl-centroid angle: $159.51^{\circ}$ ). Figure 26 shows the crystal packing of $\mathrm{S}_{\mathrm{CHCl} 3}$.

The crystal data of all the crystal structures solved for BL are summarized in Table S15 (from SCXRD) and Table S16 (from PXRD) of the Supplementary Material.

The three anhydrous polymorphs of BL crystallize in the same space group $P 2_{1} / c$ and Form II shows a unit cell similar to Form III except for the parameter "a" which is approximately twice as much as in Form III. This results in a cell for Form II with double volume than forms I and III and with $\mathrm{Z}=8$.

On the other hand, both heterosolvates $\mathrm{S}_{3 \mathrm{CHCl}-\mathrm{H} 2 \mathrm{O}}$ and $\mathrm{S}_{\mathrm{CHCl} 3-\mathrm{H} 2 \mathrm{O}}$ crystallize in the same orthorhombic space group Pna2 $2_{1}$ showing similar unit cell parameters, while the monosolvate $\mathrm{S}_{\mathrm{CHCl} 3}$ crystallizes in $P 2_{1}$, the three solvates with $\mathrm{Z}=4$.

BL is a molecule which shows an imbalance between hydrogen bond donors and acceptor groups, having only one $\mathrm{N}-\mathrm{H}$ donor group. All the structures solved are zwitterionic and BL molecules are linked by hydrogen bonds involving the carboxylate oxygen and the piperidinium nitrogen. The incorporation of water and chloroform molecules in the solvates of BL can be attributed to the imbalance in the ratio of donors and acceptors groups. Water molecules act as hydrogen bond donors in both heterosolvates, interacting with the nitrogen of the benzimidazol of BL. Instead, chloroform molecules form hydrogen bonds with the carboxylate in all solvates. Some halogen bonds are also observed in these structures, confirming that halogen bonding is one of the stabilizing interactions in chloroform solvates. However, as it has been stated [30], halogen bonding does not seem to be sufficiently strong to retain the solvent in the crystals on its own as other short contacts are also present. In fact, the two chloroform molecules in $\mathrm{S}_{3 \mathrm{CHCl3}-\mathrm{H} 2 \mathrm{O}}$ which are not linked by hydrogen bonds to the carboxylate, are lost when this solvate is removed from the solution. On the other hand, a water molecule captured from the air is incorporated in the crystal structure of $\mathrm{S}_{\mathrm{CHCl} 3}$ when taking it out from the solution, probably to further stabilize its structure. In fact, $\mathrm{S}_{\mathrm{CHCl} 3}$ can be considered a hygroscopic solid form as it has the ability 
to take up and retain water vapor. This is also true for many other compounds such as 1,10-phenanthroline [27].

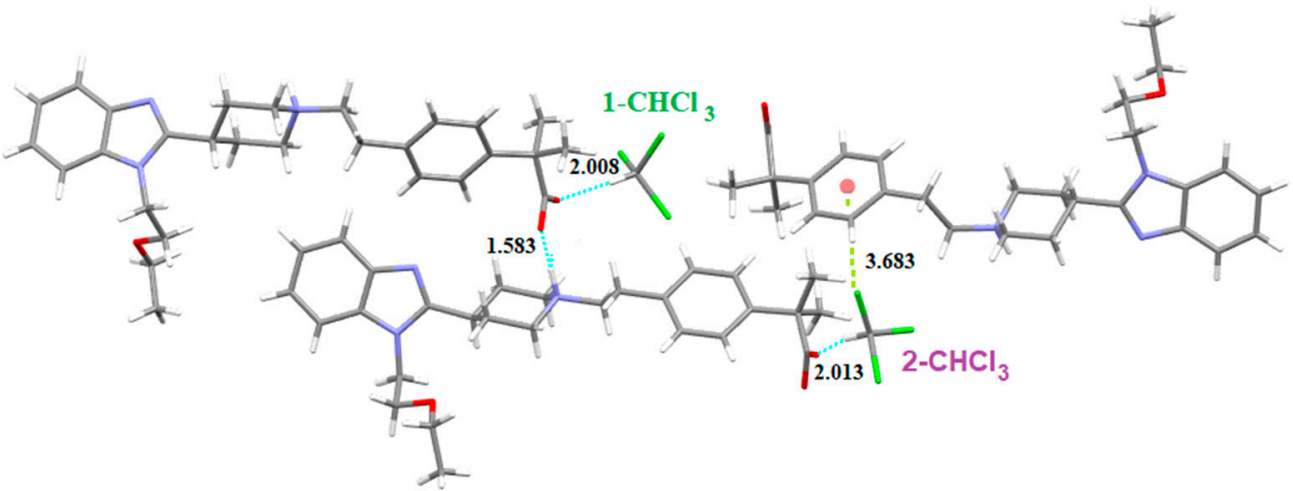

Figure 25. Intermolecular interactions (distances in $\AA$ ) observed in solvate $\mathrm{S}_{\mathrm{CHCl} 3}$.

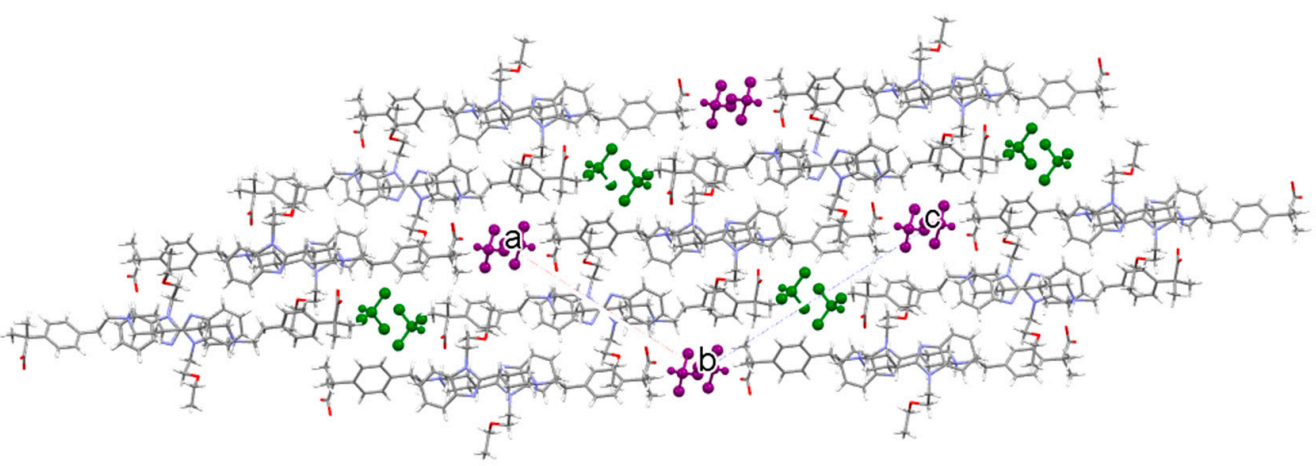

Figure 26. Crystal packing of $\mathrm{S}_{\mathrm{CHCl}}$ along the $\mathrm{b}$ axis. Green color for 1- $\mathrm{CHCl}_{3}$ and purple color for $2-\mathrm{CHCl}_{3}$.

\section{Conclusions}

Knowledge of even highly unstable and transient solvates is crucial for understanding the formation of a specific solid form and for developing pharmaceuticals and needs to be considered. Solvates that desolvate readily as soon as they are removed from the mother liquor can easily be overlooked in polymorph screening programs, and wrong conclusions concerning the solvent effects on the nucleation of individual solid forms may result. The current study clearly indicates the existence of two elusive chloroform solvates of $\mathrm{BL}$, the heterosolvate $\mathrm{S}_{3 \mathrm{CHCl} 3-\mathrm{H} 2 \mathrm{O}}$ and the monosolvate $\mathrm{S}_{\mathrm{CHCl}}$, both transforming into solvate $\mathrm{S}_{\mathrm{CHCl} 3-\mathrm{H} 2 \mathrm{O}}$ when being exposed to ambient conditions, outside the solution of crystallization. Thus, three chloroform solvates of BL with diverse stoichiometry have been discovered. Solvate formation may be easily rationalized based on a mismatch of $\mathrm{H}$-bonding donor or acceptor groups. The reason for solvate formation in BL is the lack of H-bonding donor groups. The analyses of their crystal structures when comparing with the anhydrous forms shows that $\mathrm{S}_{\mathrm{CHCl}-\mathrm{H} 2 \mathrm{O}}$, the more stable solvate, incorporates one water molecule and one chloroform molecule to satisfy the acceptor capacities of the benzimidazole and the carboxylate, respectively. Thus, this study adds more data about the structural reasons for hydrate formation. Interesting and novel, solvate $\mathrm{S}_{\mathrm{CHCl}-\mathrm{H} 2 \mathrm{O}}$ can serve as a useful intermediate towards any of the three anhydrous forms of BL, provided the right conditions are chosen.

Supplementary Materials: The following are available online at https:/ /www.mdpi.com/article/10 .3390 / cryst11040342/s1. Details of the solid form screening are shown in Tables S1-S14. Tables S15 and S16 summarize the crystal data of all the crystal structures solved in the present study for BL from SCXRD and from PXRD, respectively. 
Author Contributions: Conceptualization, C.P.; methodology, C.P., A.P. and A.B.; software, C.P., M.F.-B. and O.V.; validation, C.P., A.P. and A.B.; formal analysis, C.P., A.P., A.B., M.F.-B. and O.V.; investigation, C.P., A.P. and A.B.; data curation, C.P., A.P. and A.B.; writing-original draft preparation, C.P.; writing-review and editing, C.P.; supervision, C.P. All authors have read and agreed to the published version of the manuscript.

Funding: This research received no external funding.

Acknowledgments: ALBA synchrotron is acknowledged for the provision of beamtime.

Conflicts of Interest: The authors declare no conflicts of interest.

\section{References}

1. Singhal, D.; Curatolo, W. Drug polymorphism and dosage form design: A practical perspective. Adv. Drug Deliv. Rev. 2004, 56, 335-347. [CrossRef]

2. $\quad$ Bladgen, N.; Davey, R.J. Polymorph Selection: Challenges for the Future? Cryst. Growth Des. 2003, 3, $873-885$.

3. Zalte, A.G.; Darekar, A.B.; Gondkar, S.B.; Saudagar, R.B. Cocrystals: An Emerging Approach to Modify Physicochemical Properties of Drugs. Am. J. PharmTech Res. 2014, 4, 2056-2072.

4. Rodriguez-Spong, B.; Price, C.P.; Jayasankar, A.; Matzger, A.J.; Rodriguez-Hornedo, N. General principles of pharmaceutical solid polymorphism: A supramolecular perspective. Adv. Drug Delivery Rev. 2004, 56, 241-274. [CrossRef]

5. Grodowska, K.; Parezewski, A. Organic solvents in the pharmaceutical industry. Acta Pol. Pharm. Drug Res. 2010, 67, 3-12.

6. Zvoníček, V.; Skořepová, E.; Dušek, M.; Babor, M.; Žvátora, P.; Šoóš, M. First crystal structures of pharmaceutical ibrutinib: Systematic solvate screening and characterization. Cryst. Growth Des. 2017, 17, 3116-3127. [CrossRef]

7. Wang, Y.; Chi, Y.; Zhang, W.; Yang, Q.; Yang, S.; Su, C.; Lin, Z.; Gu, J.; Hu, C. Structural diversity of diosgenin hydrates: Effect of initial concentration, water volume fraction, and solvent on crystallization. Cryst. Growth Des. 2016, 16, 1492-1501. [CrossRef]

8. Berzins, A.; Trimdale, A.; Kons, A.; Zvanina, D. On the formation and desolvation mechanism of organic molecule solvates: A structural study of methyl cholate solvates. Cryst. Growth Des. 2017, 17, 5712-5724. [CrossRef]

9. Tieger, E.; Kiss, V.; Pokol, G.; Finta, Z.; Rohlíček, J.; Skořepová, E.; Dušek, M. Rationalization of the formation and stability of bosutinib solvated forms. CrystEngComm 2016, 18, 9260-9274. [CrossRef]

10. Council of Europe. Residual Solvents. In European Pharmacopoeia; Council of Europe: Strasbourg, France, $2013 ;$ p. 5967.

11. Morissette, S.L.; Almarsson, O.; Peterson, M.L.; Remenar, J.F.; Read, M.J.; Lemmo, A.V.; Ellis, S.; Cima, M.J.; Gardner, C.R. High-throughput crystallization: Polymorphs, salts, co-crystals and solvates of pharmaceutical solids. Adv. Drug Deliv. Rev. 2004, 56, 275-300. [CrossRef] [PubMed]

12. Wolthers, O.D. Bilastine: A new nonsedating oral $\mathrm{H} 1$ antihistamine for treatment of allergic rhinoconjunctivitis and urticaria. BioMed Res. Int. 2013, 2013, 1-6. [CrossRef]

13. Corcóstegui, R.; Labeaga, L.; Innerárity, A.; Berisa, A.; Orjales, A. Preclinical pharmacology of bilastine, a new selective histamine H 1 receptor antagonist. Drugs R D 2005, 6, 371-384. [CrossRef] [PubMed]

14. Orjales, A.; Rubio, V.; Bordell, M. Benzimidazole Derivatives with Antihistaminic Activity. EP 0818454B1, 3 June 1997.

15. Orjales, A.; Bordell, M.; Canal, G.; Blanco, H. Polymorph of Acid 4-[2-[4-[1-(2-Ethoxyethyl)-1h-Benzimidazole-2-Il]-1Piperidinyl]Ethyl]-\$G(A), \$G(A)-Dimethyl-Benzeneacetic. WO 2003/089425, 30 October 2003.

16. Fauth, F.; Peral, I.; Popescu, C.; Knapp, M. The new Material Science Powder Diffraction beamline at ALBA Synchrotron. Powder Diffr. 2013, 28, S360-S370. [CrossRef]

17. Boultif, A.; Louër, D.J. Powder pattern indexing with the dichotomy method. J. Appl. Crystallogr. 2004, 37, 724-731. [CrossRef]

18. Vallcorba, O.; Rius, J.; Frontera, C.; Peral, I.; Miravitlles, C. DAJUST: A suite of computer programs for pattern matching, space-group determination and intensity extraction from powder diffraction data. J. Appl. Crystallogr. 2012, 45, 844-848. [CrossRef]

19. Vallcorba, O.; Rius, J.; Frontera, C.; Miravitlles, C. TALP: A multisolution direct-space strategy for solving molecular crystals from powder diffraction data based on restrained least squares. J. Appl. Crystallogr. 2012, 45, 1270-1277. [CrossRef]

20. Sheldrick, G.M. A Short History of SHELX. Acta Crystallogr. 2008, A64, 112-122. [CrossRef] [PubMed]

21. Hübschle, C.B.; Sheldrick, G.M.; Dittrich, B.J. ShelXle: A Qt graphical user interface for SHELXL. J. Appl. Crystallogr. 2011, 44, 1281-1284. [CrossRef]

22. Burger, A.; Ramberger, R. On the polymorphism of pharmaceuticals and other molecular crystals. I. Mikrochim. Acta 1979, $259-271$. [CrossRef]

23. Yu, L.J. Inferring thermodynamic stability relationship of polymorphs from melting data. J. Pharm. Sci. 1995, 84, 966-974. [CrossRef]

24. Haleblian, J.; Crone, W.M. Pharmaceutical applications of polymorphism. J. Pharm. Sci. 1969, 58, 911-929. [CrossRef]

25. Zencirci, N.; Griesser, U.J.; Gelbrich, T.; Kahlenberg, V.; Jetti, R.K.R.; Apperley, D.C.; Harris, R.K. New solvates of an old drug compound (phenobarbital): Structure and stability. J. Phys. Chem. B 2014, 118, 3267-3280. [CrossRef] [PubMed]

26. Ward, M.R.; Oswald, D.H. Hidden solvates and transient forms of trimesic acid. Crystals 2020, 10, 1098. [CrossRef] 
27. Braun, D.E.; Schneeberger, A.; Griesser, U.J. Understanding the role of water in 1, 10-phenanthroline monohydrate. CrystEngComm 2017, 19, 6133-6145. [CrossRef] [PubMed]

28. Petkune, S.; Bobrovs, R.; Actins, A. Organic solvents vapor pressure and relative humidity effects on the phase transition rate of $\alpha$ and $\beta$ forms of tegafur. Pharm. Dev. Technol. 2012, 17, 625-631. [CrossRef] [PubMed]

29. Hunter, C.A.; Sanders, J.K.M. The nature of. pi.-. pi. interactions. J. Am. Chem. Soc. 1990, 112, 5525-5534. [CrossRef]

30. Takieddin, K.; Zhimyak, Y.Z.; Fábián, L. Prediction of hydrate and solvate formation using statistical models. Cryst. Growth Des. 2016, 16, 70-81. [CrossRef] 